NASA/TM-2004-213301

\title{
Inverter Output Filter Effect on PWM Motor Drives of a Flywheel Energy Storage System
}

Walter Santiago

Glenn Research Center, Cleveland, Ohio 
Since its founding, NASA has been dedicated to the advancement of aeronautics and space science. The NASA Scientific and Technical Information (STI) Program Office plays a key part in helping NASA maintain this important role.

The NASA STI Program Office is operated by Langley Research Center, the Lead Center for NASA's scientific and technical information. The NASA STI Program Office provides access to the NASA STI Database, the largest collection of aeronautical and space science STI in the world. The Program Office is also NASA's institutional mechanism for disseminating the results of its research and development activities. These results are published by NASA in the NASA STI Report Series, which includes the following report types:

- TECHNICAL PUBLICATION. Reports of completed research or a major significant phase of research that present the results of NASA programs and include extensive data or theoretical analysis. Includes compilations of significant scientific and technical data and information deemed to be of continuing reference value. NASA's counterpart of peerreviewed formal professional papers but has less stringent limitations on manuscript length and extent of graphic presentations.

- TECHNICAL MEMORANDUM. Scientific and technical findings that are preliminary or of specialized interest, e.g., quick release reports, working papers, and bibliographies that contain minimal annotation. Does not contain extensive analysis.

- CONTRACTOR REPORT. Scientific and technical findings by NASA-sponsored contractors and grantees.
- CONFERENCE PUBLICATION. Collected papers from scientific and technical conferences, symposia, seminars, or other meetings sponsored or cosponsored by NASA.

- SPECIAL PUBLICATION. Scientific, technical, or historical information from NASA programs, projects, and missions, often concerned with subjects having substantial public interest.

- TECHNICAL TRANSLATION. Englishlanguage translations of foreign scientific and technical material pertinent to NASA's mission.

Specialized services that complement the STI Program Office's diverse offerings include creating custom thesauri, building customized databases, organizing and publishing research results ... even providing videos.

For more information about the NASA STI Program Office, see the following:

- Access the NASA STI Program Home Page at http://www.sti.nasa.gov

- E-mail your question via the Internet to help@sti.nasa.gov

- Fax your question to the NASA Access Help Desk at 301-621-0134

- Telephone the NASA Access Help Desk at 301-621-0390

- Write to:

NASA Access Help Desk

NASA Center for AeroSpace Information 7121 Standard Drive

Hanover, MD 21076 
NASA/TM-2004-213301

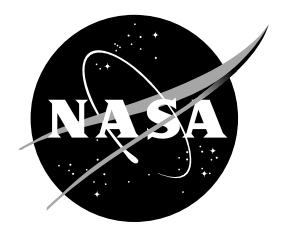

\section{Inverter Output Filter Effect on PWM Motor Drives of a Flywheel Energy Storage System}

Walter Santiago

Glenn Research Center, Cleveland, Ohio

Prepared for the

Second International Energy Conversion Engineering Conference

sponsored by the American Institute of Aeronautics and Astronautics

Providence, Rhode Island, August 16-19, 2004

National Aeronautics and

Space Administration

Glenn Research Center 
This report contains preliminary findings, subject to revision as analysis proceeds.

Trade names or manufacturers' names are used in this report for identification only. This usage does not constitute an official endorsement, either expressed or implied, by the National Aeronautics and Space Administration.

NASA Center for Aerospace Information 7121 Standard Drive

Hanover, MD 21076
Available from

National Technical Information Service 5285 Port Royal Road Springfield, VA 22100 


\title{
Inverter Output Filter Effect on PWM Motor Drives of a Flywheel Energy Storage System
}

\author{
Walter Santiago \\ National Aeronautics and Space Administration \\ Glenn Research Center \\ Cleveland, Ohio 44135
}

\begin{abstract}
NASA Glenn Research Center (GRC) has been involved in the research and development of high speed flywheel systems for small satellite energy storage and attitude control applications. One research and development area has been the minimization of the switching noise produced by the pulsed width modulated (PWM) inverter that drives the flywheel permanent magnet motor/generator (PM M/G). This noise can interfere with the flywheel M/G hardware and the system avionics hampering the full speed performance of the flywheel system. One way to attenuate the inverter switching noise is by placing an $\mathrm{AC}$ filter at the three phase output terminals of the inverter with the filter neutral point connected to the DC link (DC bus) mid-point capacitors. The main benefit of using an AC filter in this fashion is the significant reduction of the inverter's high $\mathrm{dv} / \mathrm{dt}$ switching and its harmonics components. Additionally, common mode (CM) and differential mode (DM) voltages caused by the inverter's high dv/dt switching are also reduced. Several topologies of AC filters have been implemented and compared. One AC filter topology consists of a two-stage R-L$\mathrm{C}$ low pass filter. The other topology consists of the same two-stage R-L-C low pass filter with a series connected trap filter (an inductor and capacitor connected in parallel). This paper presents the analysis, design and experimental results of these $\mathrm{AC}$ filter topologies and the comparison between the no filter case and conventional AC filter.
\end{abstract}

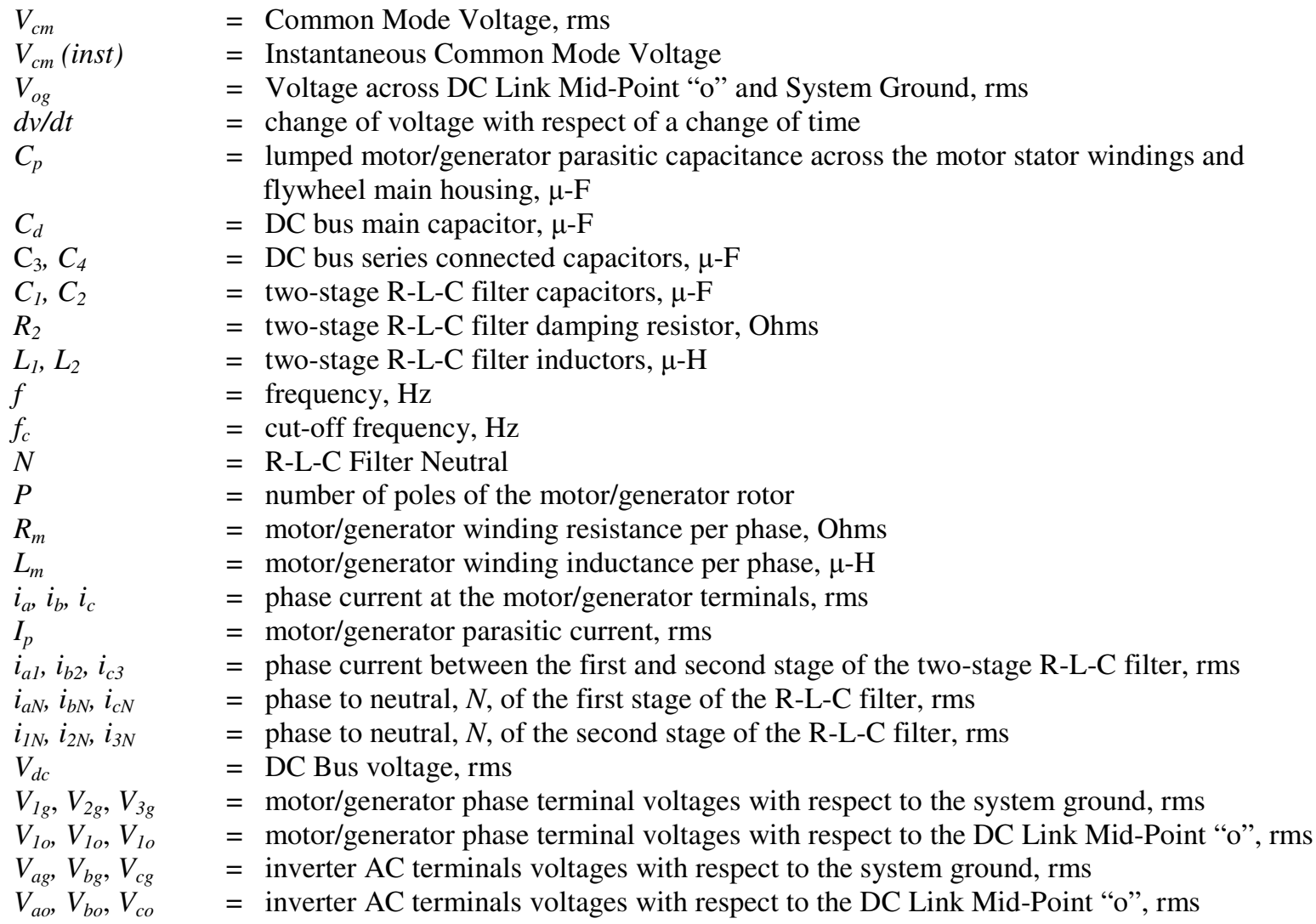


$V^{\prime}{ }_{1 g}, V_{2 g}^{\prime}, V_{3 g}^{\prime}=$ R-L-C filter output phase voltages with respect to the system ground, rms

$V^{\prime}{ }_{1 o}, V_{2 o}, V_{30}^{\prime}=$ R-L-C filter output phase voltages with respect to the DC Link Mid-Point "o", rms

$V_{a g}^{\prime}, V_{b g}^{\prime}, V_{c g}^{\prime}=$ R-L-C filter first stage output voltage with respect to the system ground, rms

$V_{a o}^{\prime}, V_{b o}^{\prime}, V_{c o}^{\prime}=$ R-L-C filter first stage output voltage with respect to the DC Link Mid-Point "o", rms

$i_{o l}, i_{o 2}=$ neutral current of the first and second stage of the R-L-C filter, rms

$i_{o} \quad=$ total neutral current, rms

\section{Introduction}

NASA Glenn Research Center (GRC) has been involved in the research and development of flywheel systems as 1 an alternative for batteries (energy storage) and control momentum gyros (attitude control) in small satellites systems [1]. A flywheel system contains several components that are essential for its success. These components are the motor/generator $(\mathrm{M} / \mathrm{G})$, the magnetic bearings $(\mathrm{MB})$, the flywheel rotor and the touchdown bearings (TB). The M/G system, with the help of a DC to AC inverter, manages the satellite charge, discharge and attitude control modes. The MB System keeps the flywheel rotor levitated to ensure high speed (approximately 60,000 rpm) rotor operation. The touchdown bearing system restrains the flywheel rotor when the MB is un-powered or fails. Figure 1 shows how the components are integrated in a flywheel system with feedback control loops for the M/G and MB system.

The main function of the M/G and the DC to AC inverter is to transfer energy between the satellite DC bus and the flywheel mass. Any excess electrical energy that is collected by the satellite solar array will flow from the inverter into the $\mathrm{M} / \mathrm{G}$ and is converted and stored as kinetic energy by spinning up the flywheel. When the solar array is unable to supply the energy demanded by the satellite loads the flywheel will transfer back its stored energy from the flywheel into the DC power bus through the $\mathrm{M} / \mathrm{G}$ and the inverter.

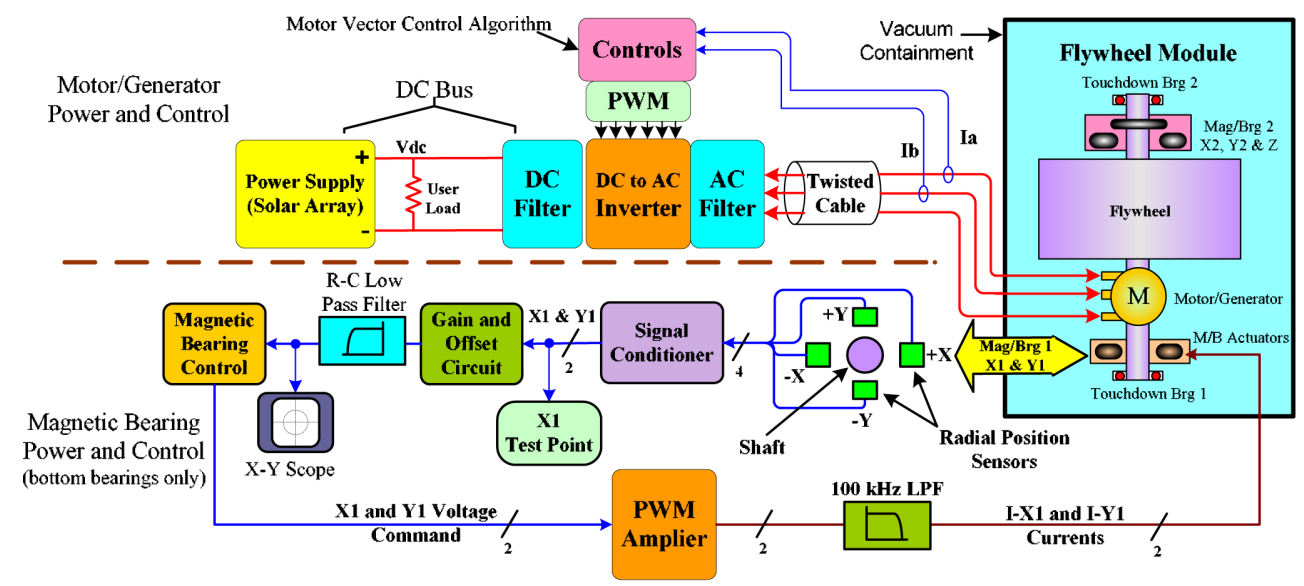

Figure 1. Representation of a Flywheel System

With the increase of operational speed and power ratings of solid state power switching devices, DC to AC inverters can employ high switching frequency Pulsed Width Modulation (PWM) schemes to provide better M/G drive performance, enhanced motor adjustable-speed control bandwidth and reduced ripple on the motor phase currents. Although the PWM inverters can provide the above benefits to the $\mathrm{M} / \mathrm{G}$ system they also have some adverse effects on the $\mathrm{M} / \mathrm{G}$ and $\mathrm{MB}$ system. If the inverter is coupled directly to the $\mathrm{M} / \mathrm{G}$, high values of Common Mode (CM) and Differential Mode (DM) voltage noise are injected to the system due to the high dv/dt switching of the inverter (fig. 2). These high values of CM and DM voltages can have the following effects on the on the flywheel M/G and MB system:

- Deterioration of the motor winding isolation with the potential of line to flywheel chassis failure.

- Reduced motor efficiency.

- Increased $\mathrm{M} / \mathrm{G}$ eddy current and hysteresis losses.

- High leakage current from the motor windings through the flywheel main chassis due to parasitic capacitances.

- EMI on the magnetic bearing flywheel position sensors. 
The first four effects are well known for any conventional motor-inverter configurations using a PWM switching scheme. However, for a flywheel system the high $\mathrm{dv} / \mathrm{dt}$ switching of the inverter introduces an additional impact which could be even more harmful. This major impact is noticed in the magnetic bearing system of the flywheel. A high speed flywheel system relies on the use of active magnetic bearings (MB) with feedback control (see fig. 1). The active MB system allows high speed (60,000 RPM) flywheel operation and long life performance by replacing the use of conventional ball bearings. The use of an inverter that applies Pulsed Width Modulation (PWM) voltage to the $\mathrm{M} / \mathrm{G}$ can seriously affect the performance of the magnetic bearing system through the introduction of noise on the MB eddy current position sensors. The eddy current position sensors employ a high frequency magnetic field to measure the distance or displacement of a target (the flywheel shaft). When the eddy current sensors are in close proximity to the $\mathrm{M} / \mathrm{G}$, high $\mathrm{dv} / \mathrm{dt}$ signals from the inverter can provide electromagnetic interference affecting the accuracy of the measurement provided by the position sensors. False distance readings by the eddy current position sensors can lead to unnecessary control action by the MB actuators which can lead to a critical failure if it causes MB system instability. In less severe cases it will lead to increased losses in the MB system.

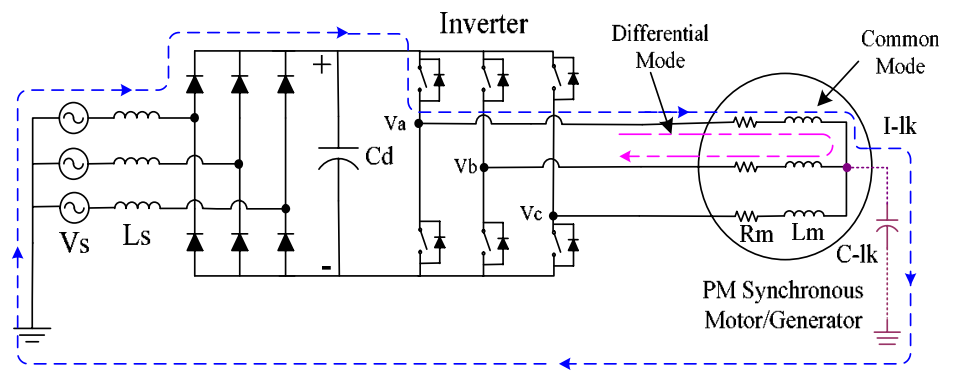

Figure 2. System Representation of a Conventional Inverter/Motor Configuration Showing Common Mode, Differential Mode and Motor Leakage Capacitance.

To reduce the impact of the CM and DM noise due to high dv/dt's, a three phase AC filter coupled between the $\mathrm{DC}$ to $\mathrm{AC}$ inverter and the $\mathrm{M} / \mathrm{G}$ can be implemented (fig. 1). There are several AC filter topologies that have been used but some of them only address CM or DM noise but not both at the same time [2], [3], and [5]. One paper address the reduction of CM and DM noise but the use of an extra half bridge switch increases the sophistication and requires an additional control scheme [4]. Rendusara et al. [6] proposed the use of an R-L-C filter in a star configuration with the filter neutral connected to the mid-point of the two series DC capacitors in a 480-V 20-hp Motor PWM drive system (fig. 3). This topology shows a great reduction of CM and DM voltages and leakage current by carefully selecting the values of $\mathrm{R}, \mathrm{L}$ and $\mathrm{C}$ of the filter. One advantage of this filter topology is that it can be connected at the inverter $\mathrm{AC}$ terminals without consideration of the length of the $\mathrm{AC}$ cables and transmission issues that it can introduce to the M/G [7]. The simplicity of this AC filter topology and the potential performance improvement that it brings to the inverter and motor system make this a good candidate for the NASA GRC flywheel system.

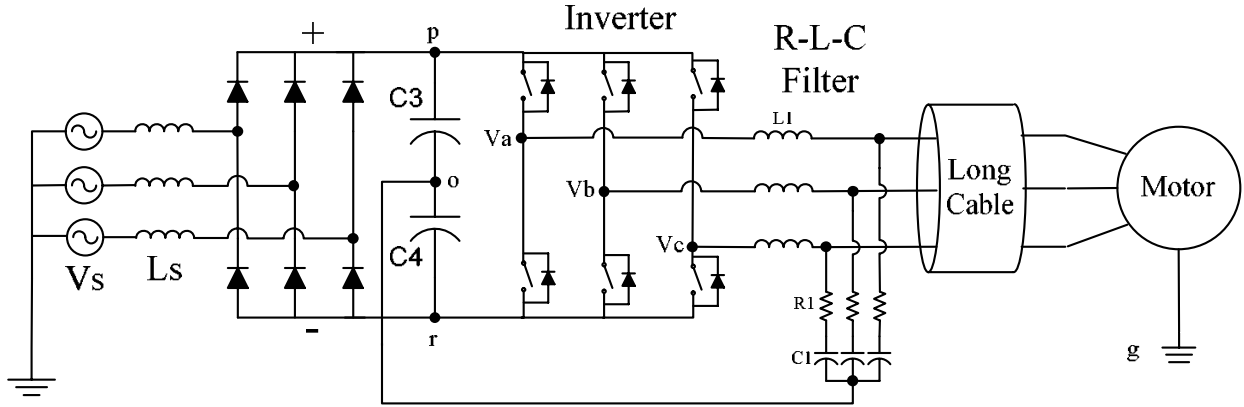

Figure 3. Inverter and Motor Configuration with a Star Configuration R-L-C Filter with its Neutral Connected to the DC Link Mid-Point Capacitors.

Taking the figure $3 \mathrm{AC}$ filter as the baseline, different approaches were tested in order to determine the best topology for the NASA GRC flywheel system. The following sections will explain the theoretical concept and 
impact on the common mode (CM) and differential mode (DM) in a PWM inverter and motor system when an AC filter is not employed and when different AC filter topologies are employed. Also test data shows a comparison between the different AC filter and no AC filter cases in terms of reduction of motor stresses, losses and leakage currents without affecting the phase shift in the motor control loop. Finally, the AC filter topologies are compared on the basis of noise reduction on the position sensors of the MB system.

\section{ANALYSIS}

Figure 4 shows the inverter and M/G configuration used on the NASA flywheel system without an AC filter. An isolated DC power supply is connected to the inverter to simulate the satellite solar array system and 15 feet of 10 AWG twisted cable is connected between the motor/generator and the inverter. At the DC terminals of the inverter two capacitors $\left(C_{3}\right.$ and $\left.C_{4}\right)$ are connected in series, each one rated for 1,200 Vdc and with their mid-point denoted by "o". The motor/generator is a two pole permanent magnet (PM) synchronous motor rated at $5.85 \mathrm{~kW}$ with an operational line to line voltage of $79.26 \mathrm{Vrms}$ and a speed range of 0 to $60,000 \mathrm{rpm}$. The relationship between mechanical speed and AC electrical speed, or fundamental frequency, is given by

$$
f=P^{*} R P M / 120
$$

where $f$ is the electrical frequency in $\operatorname{Hertz}(\mathrm{Hz}), P$ is the motor/generator number of poles and $R P M$ is the rated mechanical speed in revolutions per minute. The NASA GRC flywheel M/G is a two pole machine so the range of $\mathrm{AC}$ electrical frequency is between 0 and $1 \mathrm{kHz}$.

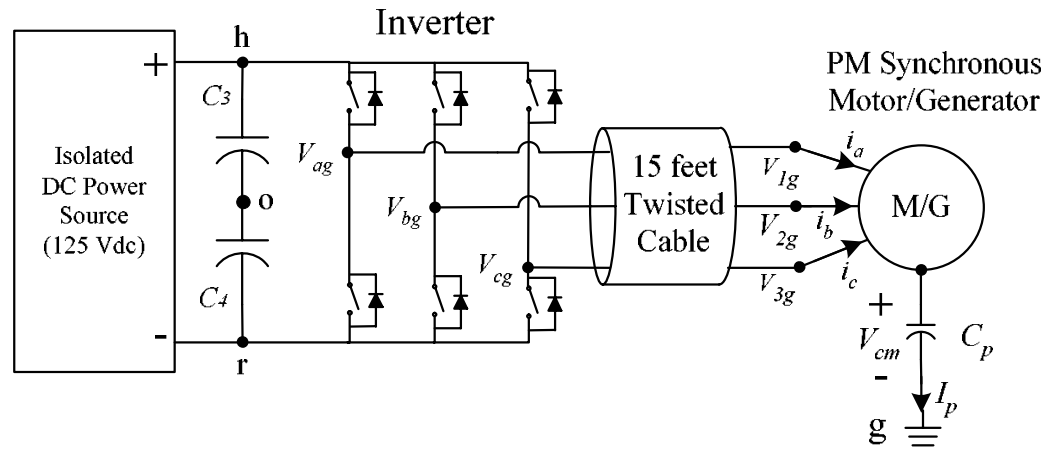

Figure 4. Flywheel System Inverter and Motor/Generator Configuration without an AC Filter

\section{A. Common Mode Voltage at the Motor Terminals}

This section expresses the common mode voltage $\left(\mathrm{V}_{\mathrm{cm}}\right)$ of the flywheel system in terms of the motor terminal voltages with respect to DC mid-point "o" when no filter is between the inverter and the M/G. This common mode voltage is located across the leakage capacitance $\left(C_{p}\right)$ located between the $M / G$ and the flywheel housing. The common mode voltage $\left(\mathrm{V}_{\mathrm{cm}}\right)$ can be derived as follows:

$$
\begin{aligned}
& V_{1 g}-V_{c m}=R_{m} i_{a}+L_{m} \frac{d i_{a}}{d t} \\
& V_{2 g}-V_{c m}=R_{m} i_{b}+L_{m} \frac{d i_{b}}{d t} \\
& V_{3 g}-V_{c m}=R_{m} i_{c}+L_{m} \frac{d i_{c}}{d t}
\end{aligned}
$$

where $V_{l g}, V_{2 g}$, and $V_{3 g}$ are the voltages at the motor terminals with respect to ground "g" and $R_{m}$ and $L_{m}$ are the per phase motor winding resistance and inductance respectively. Adding equations (2), (3) and (4) we obtain

$$
V_{1 g}+V_{2 g}+V_{3 g}-3 V_{c m}=\left(R_{m}+L_{m} \frac{d}{d t}\right)\left(i_{a}+i_{b}+i_{c}\right)
$$


Since the $\mathrm{M} / \mathrm{G}$ is a balanced system $i_{a}+i_{b}+i_{c} \approx 0$ and $I_{\mathrm{p}} \approx 0$ therefore the common mode voltage can be expressed as

$$
V_{c m}=\frac{V_{1 g}+V_{2 g}+V_{3 g}}{3}
$$

The motor terminal voltages with respect to ground " $g$ " can also be expressed in terms of the DC link middle point "o" capacitors as follows

$$
\begin{aligned}
& V_{1 g}=V_{1 o}+V_{o g} \\
& V_{2 g}=V_{2 o}+V_{o g} \\
& V_{3 g}=V_{3 o}+V_{o g}
\end{aligned}
$$

Substituting equations (7), (8) and (9) into Eq. (6) results in the following expression for $V_{c m}$.

$$
V_{c m}=\frac{V_{1 o}+V_{2 o}+V_{3 o}}{3}+V_{o g}
$$

In this inverter three out of its six MOSFET switches are conducting at any given time which represents eight possible switching states. Two switching states provide cero voltage to the M/G and correspond either to all three top inverter switches on or all three bottom switches on. The remaining six switching states provide voltage to the M/G and alternate between one top switch with two bottom switches on and two top switches with one bottom switch on. With this in mind the summation of voltages at the inverter AC terminals with respect to the DC link mid-point "o" can be express as follows

$$
V_{a o}+V_{b o}+V_{c o}= \begin{cases} \pm \frac{3 V_{d c}}{2} & \text { all top or bottom switches are on } \\ \pm \frac{V_{d c}}{2} & \text { one top and two bottom switches on or vice versa }\end{cases}
$$

As mentioned before and illustrated on figure 4 the $\mathrm{M} / \mathrm{G}$ and inverter use 15 feet of $10 \mathrm{AWG}$ cable between the inverter and the motor. It has been observed that a PWM inverter and motor configuration without an AC filter can experience overvoltages due to reflections at the motor terminals which can be attributed to the high voltage dv/dt's [7]. For the NASA GRC M/G inverter configuration with a $125 \mathrm{~V}$ DC bus and no AC filter, the dv/dt can be as high as $1,126 \mathrm{~V} / \mu \mathrm{s}$ (voltage rise of 107 Volts and rise time of $.095 \mu \mathrm{s}$ ). Therefore the pulsed voltage at the motor terminal $\left(\mathrm{V}_{10}, \mathrm{~V}_{20}\right.$ and $\left.\mathrm{V}_{30}\right)$ can be approximately twice the amount of voltage seen at the inverter terminals. Consequently by using equation (11) the summation of the M/G terminals voltage with respect to the DC link mid-point "o" can be express as follows

$$
V_{1 o}+V_{2 o}+V_{3 o}= \begin{cases} \pm 3 * V_{d c} & \text { all top or bottom switches are on } \\ \pm V_{d c} & \text { one top and two bottom switches on or vice versa }\end{cases}
$$

Combining equation (12) into equation (10) the instantaneous common mode voltage can be express as 


$$
V_{c m}(\text { inst })= \begin{cases} \pm V_{d c}+V_{o g} & \text { all top or bottom switches are on } \\ \pm \frac{V_{d c}}{3}+V_{o g} & \text { one top and two bottom switches on or vice versa }\end{cases}
$$

Equation (13) expresses the common mode voltage applied to the motor in the absence of an AC filter. Notice that this common mode voltage is expressed as a function of the DC bus voltage $\left(V_{d c}\right)$, and the voltage across DC link mid-point "o" and ground $\left(\mathrm{V}_{\mathrm{og}}\right) . V_{c m}$, the voltage across the parasitic capacitance located between the M/G windings and flywheel structure, creates noise on the MB position sensors and causes $\mathrm{M} / \mathrm{G}$ winding stress due to the high $\mathrm{dv} / \mathrm{dt}$. Therefore, the lower $\mathrm{V}_{\mathrm{cm}}$ becomes the less the noise and stress there is.

\section{B. Voltage between DC Link Mid-Point “o” to Ground $(g)$ - $V_{o g}$}

$V_{o g}$ plays a very important role in the reduction of noise due to the common mode voltage effect. Based on equation (13), $V_{c m}$ is a function of the DC bus voltage $\left(V_{d c}\right)$ and the voltage between the DC Link Mod-Point "o" and the system ground $\left(V_{o g}\right)$. The larger the value of $V_{o g}$, the more noise the flywheel system will have. In figure 5(a) when the inverter is off, $V_{o g}$ shows a near sinusoidal waveform. The presence of this $60 \mathrm{~Hz}$ sinusoidal waveform at this system set up is because of the isolation of the DC power supply with respect to the building three phase AC input. Otherwise $V_{o g}$ will be a triangular waveform as seen in [6] and figure 3. If $V_{o g}$ were always a sinusoidal waveform CM noise will be much less because of its low harmonic content. Therefore, to guarantee a low common mode system noise $V_{o g}$ should be as sinusoidal as possible in order to reduce the dv/dt's effect on the system. Figure 5(b) shows $V_{o g}$ with the inverter turned on with a star configured three phase AC filter. The $V_{o g}$ for this filter configuration shows a high dv/dt superimposed on the $60 \mathrm{~Hz}$ sinusoidal waveform. In contrast, the same filter with the neutral coupled to the DC link mid-point "o" is shown in figure. 5(c). Figure 5(d) has the same filter but with an L-C trap connected in series. These two last configurations show the benefits of the AC filter with $V_{o g}$ nearly a $60 \mathrm{~Hz}$ sinusoidal waveform which results in low $\mathrm{dv} / \mathrm{dt}$ and low common mode noise $\left(V_{c m}\right)$.

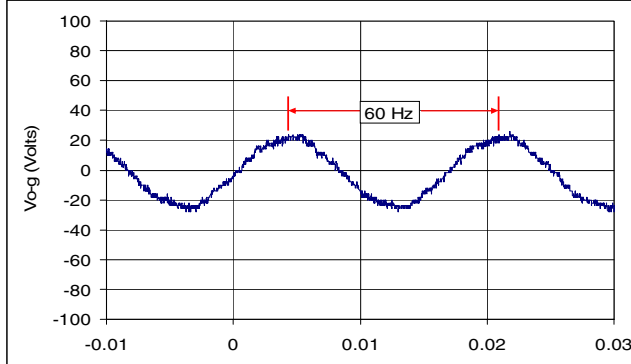

(a)

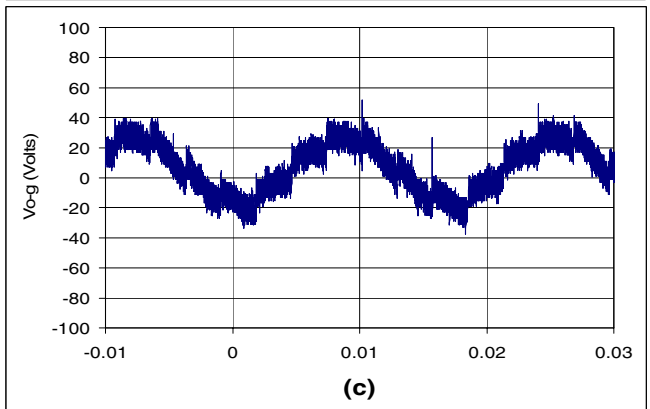

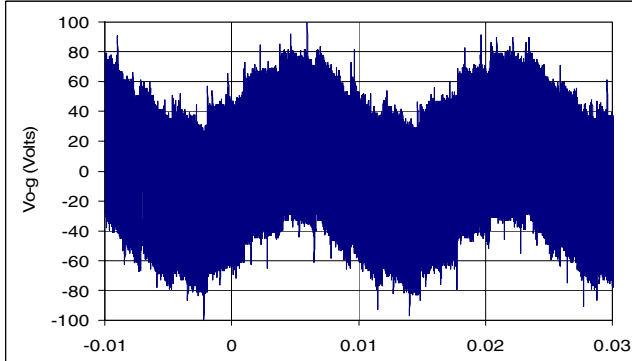

(b)

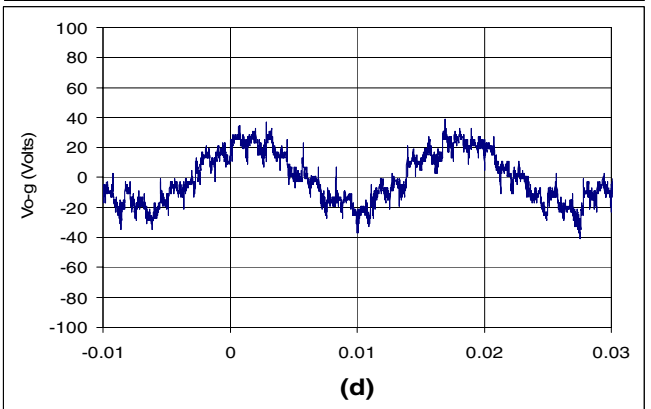

Figure 5. Voltage between DC Link Mid-Point " $\quad$ " to Ground $(g)$ versus Time $\left(V_{\text {og }}\right)$. (a) Inverter Off. (b) Inverter ON with10 kHz R-L-C Filter with Neutral NOT tied to "o".

(c) Inverter ON with10 kHz R-L-C Filter with Neutral tied to "o".

(d) Inverter ON with $10 \mathrm{kHz}$ R-L-C Filter and $65 \mathrm{kHz}$ Trap with Neutral tied to "o".

\section{Common Mode Voltage with an AC Filter and NO Neutral coupled to the DC Link Mid-Point "o"}

Figure 6 shows an $L-R-C$ filter connected between the flywheel $\mathrm{M} / \mathrm{G}$ and the inverter with no connection between the filter neutral "N" and the DC link mid-point "o". Most industries use this conventional configuration 
which suppresses the high line to line $\mathrm{dv} / \mathrm{dt}$ voltage (differential mode). The reduction of differential mode $\mathrm{dv} / \mathrm{dt}$ helps to alleviate the stresses on the motor windings and the effect of voltage reflection along the three phase line. With the proper design approach and knowledge of the system configuration the filter parameters, $L_{I}, C_{l}$ and $R_{l}$ can be selected such that the filter attenuates all the high frequency switching and provides a differential mode output of nearly sinusoidal line to line voltages at the desired fundamental frequency (between 0 to $1 \mathrm{kHz}$ for this case).

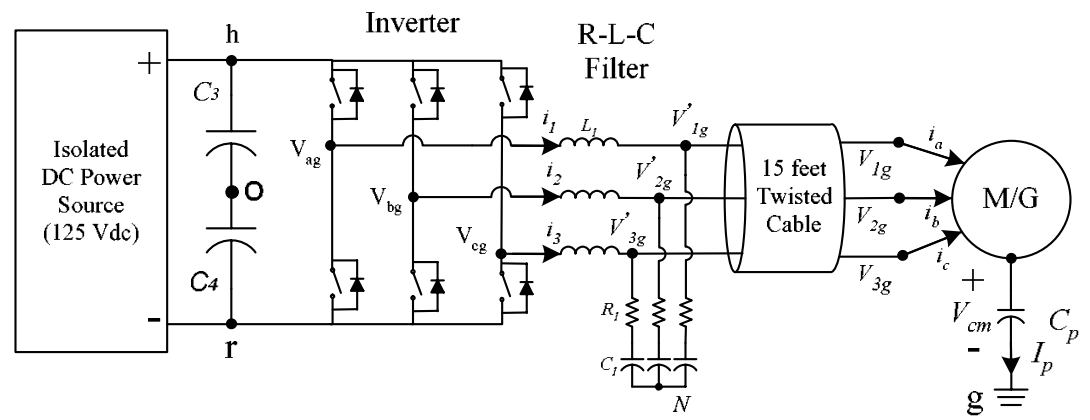

Figure 6. Inverter and Motor/Generator Configuration with an R-L-C Filter

Since the $L-R-C$ filter supplies a near sinusoidal voltage to the $\mathrm{M} / \mathrm{G}$, the filter output stage voltages $\left(V^{\prime}{ }_{1 g}, V_{2 g}{ }_{2 g}\right.$, $V_{3 g}{ }_{3 g}$ ) can be equated to the M/G terminal voltages, $V_{l g}, V_{2 g}$ and $V_{3 g}$. Therefore the common mode voltage at the motor terminals can be expresses as follows:

$$
V_{c m}=\frac{V_{1 g}+V_{2 g}+V_{3 g}}{3} \approx \frac{V_{1 g}^{\prime}+V_{2 g}^{\prime}+V_{3 g}^{\prime}}{3}
$$

The voltage relationship between the inverter terminal voltages and the output of the AC filter can be also expressed as:

$$
\begin{aligned}
& V_{a g}-V_{1 g}^{\prime}=L_{1} \frac{d i_{1}}{d t} \\
& V_{b g}-V_{2 g}^{\prime}=L_{1} \frac{d i_{2}}{d t} \\
& V_{c g}-V_{3 g}^{\prime}=L_{1} \frac{d i_{3}}{d t}
\end{aligned}
$$

Then adding equations (15), (16) and (17) results in:

$$
\left(V_{a g}+V_{b g}+V_{c g}\right)-\left(V_{1 g}^{\prime}+V_{2 g}^{\prime}+V_{3 g}^{\prime}\right)=L_{1} \frac{d}{d t}\left(i_{a}+i_{b}+i_{c}\right)
$$

For a balanced three phase system $\left(i_{a}+i_{b}+i_{c}\right) \approx 0$ and Eq. (18) becomes:

$$
\left(V_{a g}+V_{b g}+V_{c g}\right)=\left(V_{1 g}^{\prime}+V_{2 g}^{\prime}+V_{3 g}^{\prime}\right)
$$

Substituting equation (19) into equation (14) $V_{c m}$ yields:

$$
V_{c m} \approx \frac{V_{a g}+V_{b g}+V_{c g}}{3}
$$


Each inverter terminal voltages from equation (20) $\left(V_{a g}, V_{b g}\right.$, and $\left.V_{c g}\right)$ can also be expressed as the sum of its terminal voltage w.r.t. the DC link mid-point "o" plus the voltage from the mid-point "o" w.r.t. the system ground:

$$
\begin{aligned}
& V_{a g}=V_{a o}+V_{o g} \\
& V_{b g}=V_{b o}+V_{o g} \\
& V_{c g}=V_{b o}+V_{o g}
\end{aligned}
$$

Substituting equations (21), (22) and (23) into equations (20) yields:

$$
V_{c m} \approx \frac{V_{a o}+V_{b o}+V_{c o}}{3}+V_{o g}
$$

As explained in section II-A the inverter has three switches conducting at any given time corresponding to eight switching states. Therefore, by combining equation (11) into (24), the instantaneous common mode voltage $\left(V_{c m}\right)$ for an $\mathrm{M} / \mathrm{G}$ and inverter system with floating R-L-C results in:

$$
V_{c m}(\text { inst })= \begin{cases} \pm \frac{V_{d c}}{2}+V_{o g} & \text { all top or bottom switches are on } \\ \pm \frac{V_{d c}}{6}+V_{o g} & \text { one top and two bottom switches on or vice versa }\end{cases}
$$

This equation demonstrates that even though a floating R-L-C filter can be effective in reducing differential mode voltages at the motor terminals, the common mode voltages will remain high. This is the results of the high dv/dt voltage switching and the instantaneous values of $V_{o g}$ as explained on section II-B and figure 5(b). Consequently, something further improvements are required.

\section{Common Mode Voltage with an AC Filter with Neutral coupled to the DC Link Mid-Point "o"}

Figure 7 depicts the proposed R-L-C filter topology for the flywheel M/G and inverter system. This filter configuration has two distinctive features. One is the connection of the filter neutral " $N$ " to the DC Link Mid-Point "o". The other feature is the application of a two stage R-L-C filter acting as a four pole low pass AC filter (fig. 8). The details of the two stage R-L-C filter will be explained in the following sections.

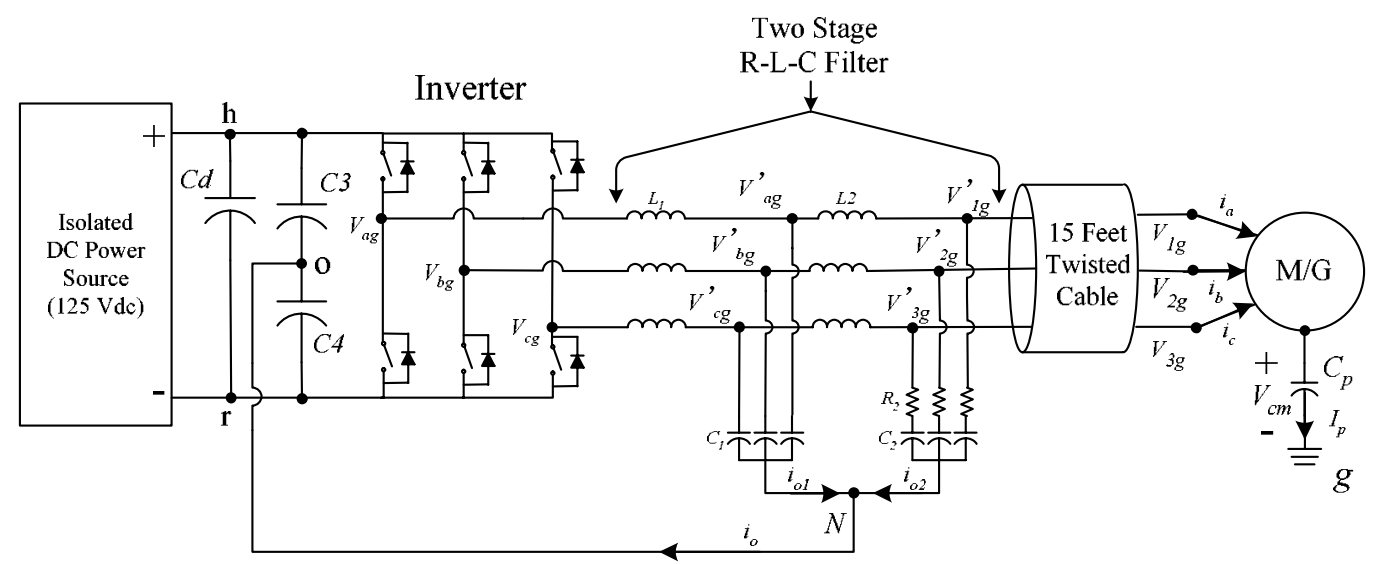

Figure 7. Proposed Three Phase R-L-C Filter for the Flywheel M/G and Inverter System

To express the common mode voltage of this flywheel configuration it is necessary to reference the filter voltages to the mid-point "o". Figure 8 is a detailed schematic of the filter. The R-L-C filter first stage output 
voltage w.r.t. the system ground $\left(V_{a g}^{\prime}, V^{\prime}{ }_{b g}, V_{c g}^{\prime}\right.$, ) and R-L-C filter the second stage output voltage w.r.t. the system ground $\left(V^{\prime}{ }_{l g}, V^{\prime}{ }_{2 g}, V^{\prime}{ }_{3 g}\right)$ can be described as:

$$
\begin{aligned}
& V_{a g}^{\prime}=V_{a o}^{\prime}+V_{o g} \\
& V_{b g}^{\prime}=V_{b o}^{\prime}+V_{o g} \\
& V_{c g}^{\prime}=V_{c o}^{\prime}+V_{o g} \\
& V_{1 g}^{\prime}=V_{1 o}^{\prime}+V_{o g} \\
& V_{2 g}^{\prime}=V_{2 o}^{\prime}+V_{o g} \\
& V_{3 g}^{\prime}=V_{3 o}^{\prime}+V_{o g}
\end{aligned}
$$

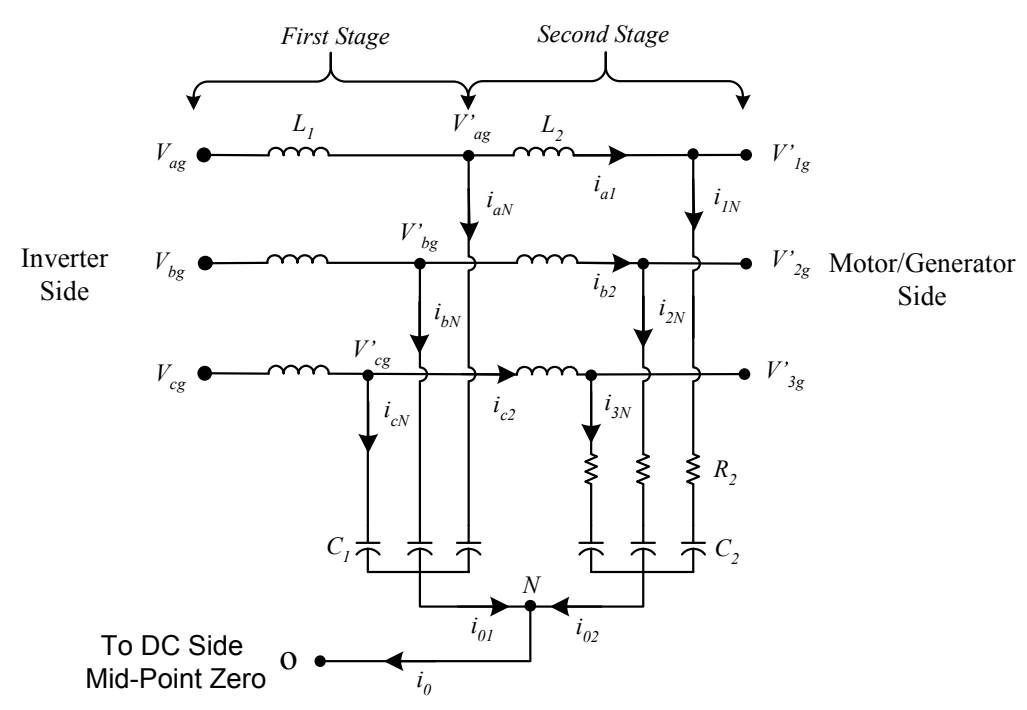

Figure 8. Detailed Schematic of the Proposed Three Phase Two Stage R-L-C Filter (Fourth Order Low Pass Filter)

Given $X=a, b$, and $c$, the first stage voltages with respect to the DC mid-point "o" $\left(V_{a o}^{\prime}, V_{b o}^{\prime}, V_{c o}^{\prime},\right)$ can be express as follows:

$$
V^{\prime}{ }_{X o}=\frac{1}{C_{1}} \int i_{X N} d t
$$

Summing all the three terminals voltages of the first stage derived from equation (32) and $i_{a N}+i_{b N}+i_{c N}=i_{o l}$ results in:

$$
V_{a o}^{\prime}+V_{b o}^{\prime}+V_{c o}^{\prime}=\frac{1}{C_{1}} \int\left(i_{a N}+i_{b N}+i_{c N}\right) d t=\frac{1}{C_{1}} \int i_{o 1} d t
$$

Given $Y=1,2$, and 3 , the second stage voltages with respect to the DC mid-point "o" $\left(V_{1 o}^{\prime}, V_{2 o}^{\prime}, V^{\prime}{ }_{3 o}\right)$ can be express as follows: 


$$
V_{Y o}^{\prime}=i_{Y N} R_{2}+\frac{1}{C_{1}} \int i_{Y N} d t
$$

Summing all the three terminals voltages of the second stage derived from equation (34) and $i_{I N}+i_{2 N}+i_{3 N}=i_{o 2}$ results in:

$$
V_{1 o}^{\prime}+V_{2 o}^{\prime}+V_{3 o}^{\prime}=R_{2}\left(i_{1 N}+i_{2 N}+i_{3 N}\right)+\frac{1}{C_{2}} \int\left(i_{a N}+i_{b N}+i_{c N}\right) d t=i_{o 2} R_{2}+\frac{1}{C_{2}} \int i_{o 2} d t
$$

The voltage relationship between the stage one and stage two filter voltages can be express as:

$$
\begin{aligned}
& V_{a o}^{\prime}-V_{1 o}^{\prime}=L_{2} \frac{d i_{a 1}}{d t} \\
& V_{b o}^{\prime}-V_{2 o}^{\prime}=L_{2} \frac{d i_{b 2}}{d t} \\
& V_{c o}^{\prime}-V_{3 o}^{\prime}=L_{2} \frac{d i_{c 3}}{d t}
\end{aligned}
$$

Adding equations (36), (37) and (38) results in:

$$
\left(V_{a o}^{\prime}+V_{b o}^{\prime}+V_{c o}^{\prime}\right)-\left(V_{1 o}^{\prime}+V_{2 o}^{\prime}+V_{3 o}^{\prime}\right)=L_{2} \frac{d}{d t}\left(i_{a 1}+i_{b 2}+i_{c 3}\right)
$$

For a balanced three phase system $\left(i_{a l}+i_{b 2}+i_{c 3}\right) \approx 0$ and equation (39) becomes

$$
\left(V_{a o}^{\prime}+V_{b o}^{\prime}+V_{c o}^{\prime}\right)=\left(V_{1 o}^{\prime}+V_{2 o}^{\prime}+V_{3 o}^{\prime}\right)
$$

Now by adding equations (33) and (35), and using the relationship of equation (40) results in the following expression

$$
V_{1 o}^{\prime}+V_{2 o}^{\prime}+V_{3 o}^{\prime}=\frac{1}{2}\left[R_{2} i_{o 2}+\frac{1}{C_{1}} \int i_{o 1} d t+\frac{1}{C_{2}} \int i_{o 2} d t\right]
$$

As in the previous case the $L-R$ - $C$ filter supplies a nearly sinusoidal voltage to the $\mathrm{M} / \mathrm{G}$ and the filter output voltages $\left(V^{\prime}{ }_{l g}, V_{2 g}^{\prime}\right.$ and $\left.V_{3 g}^{\prime}\right)$ can be equated to the M/G terminal voltages $\left(V_{l g}, V_{2 g}\right.$ and $\left.V_{3 g}\right)$. Thus equation (14), common mode voltage at the motor terminals, still applies.

Combining equations (29), (30), (31) and (41) results in the following expression for the motor terminal common mode voltage when a 2-stage filter with its neutral connected at the DC link Mid-point "o" is used.

$$
V_{c m} \approx \frac{1}{6}\left(R_{2} i_{o 2}+\frac{1}{C_{1}} \int i_{o 1} d t+\frac{1}{C_{2}} \int i_{o 2} d t\right)+V_{o g}
$$

By comparing equation (42) with the instantaneous common mode voltage equations of the no R-L-C filter case, equation (13), and the floating neutral R-L-C filter case, equation (25), it can be concluded that by using the proposed non-floating two-stage R-L-C filter topology and carefully selecting the values of the $C_{l}, L_{1}, \mathrm{C}_{2}, L_{2}$, and $R_{2}$ two major improvements can be made. They are:

- Decreased common mode voltage magnitude

- Reduced the high voltage $\mathrm{dv} / \mathrm{dt}$

An additional advantage of this non-floating R-L-C filter is that the common mode voltage (eq. 42) is dependent on controllable parameters. Therefore, by making the damping resistor $R_{2}$ small enough and the capacitance $C_{1}$ and $C_{2}$ large enough the common mode voltage can be considerably reduced in addition to the $1 / 6$ factor. This is in contrast to the previous cases given in equations (13) and (25) where the common mode voltage is not dependent on filter 
parameters. Furthermore, by connecting the filter neutral to the DC mid-point "o", $\mathrm{V}_{\mathrm{og}}$ will become more sinusoidal (fig. 5(c) and (d)).

The dv/dt reduction and the decreased common mode voltage effect given by the two-stage R-L-C filter tied to the DC mid-point "o" provides the following additional benefits for the Flywheel M/G and MB systems:

- No deterioration of the motor winding isolation.

- Increased motor efficiency.

- Reduced M/G eddy current and hysteresis losses.

- Low leakage current from the motor windings through the flywheel main chassis due to parasitic capacitances.

- Low EMI on the magnetic bearing flywheel position sensors.

\section{E. Differential Mode Voltage Effect}

The combination of the inverter's very high voltage and short rise times enabled by fast switching MOSFET's or IGBT's result in high dv/dt line to line voltage (differential mode noise). In industry applications these dv/dt voltages at the motor terminals can reach between 7,000 V/ $\mu$ s and $11,000 \mathrm{~V} / \mu$ s producing motor winding stresses and voltage reflection effects [6]. The typical alternative to suppress the high line to line $\mathrm{dv} / \mathrm{dt}$ voltage is the application of an $L-R-C$ filter with a floating neutral (no connection between its neutral "N" and the DC link midpoint "o", fig. 6). With proper design and the knowledge of the system configuration the filter parameters $L_{1}, C_{l}, L_{2}$, $C_{2}$ and $R_{2}$ (fig. 7) can be selected so that the filter attenuates all the high frequency switching and provides a differential mode output of a nearly sinusoidal line to line voltages at the desired fundamental frequency (between 0 to $1 \mathrm{kHz}$ for this flywheel case).

\section{R-L-C Filter Design}

The NASA Glenn Research Center flywheel M/G and MB set up is shown in figure 1. As described previously, a proper R-L-C filter design is crucial for the success of this flywheel system. The DC to AC inverter DM and CM noise must be minimized so that the M/G can operate with low stresses and losses and the MB position sensors can function with the minimum amount of interference which can results in false displacement readings of the flywheel shaft.

The DC to AC inverter will have a switching frequency of $65 \mathrm{kHz}$ and the DC bus voltage will be $125 \mathrm{Vdc}$. The flywheel M/G system uses a two-pole PM synchronous motor capable of operating at a fundamental frequency between 0 to $1 \mathrm{kHz}$ equal to spinning the flywheel from 0 to 60,000 RPM. The major design criteria for the R-L-C filter was the selection of the cut-off frequency. This cut-off frequency has to fall between the maximum fundamental frequency of the motor and the inverter's switching frequency with good attenuation at the high frequency range and minimum attenuation between 0 to $1 \mathrm{kHz}$. Another filter design aspect to consider is the phase lag effect. Major phase lag in the fundamental operating range $(0$ to $1 \mathrm{kHz})$ can affect the proper operation of the flywheel M/G controls.

The values of the filter R, L's and C's were selected to produce a near sinusoidal line to line voltage and a small common mode voltage, equation (42).

\section{A. Two-Stage R-L-C Filter Topology (Four-pole Low Pass Filter)}

The two-stage R-L-C filter topology is shown in figures. 7 and 8 . Figure 9 also shows the single phase representation of the filter with its transfer function given in equation (43).

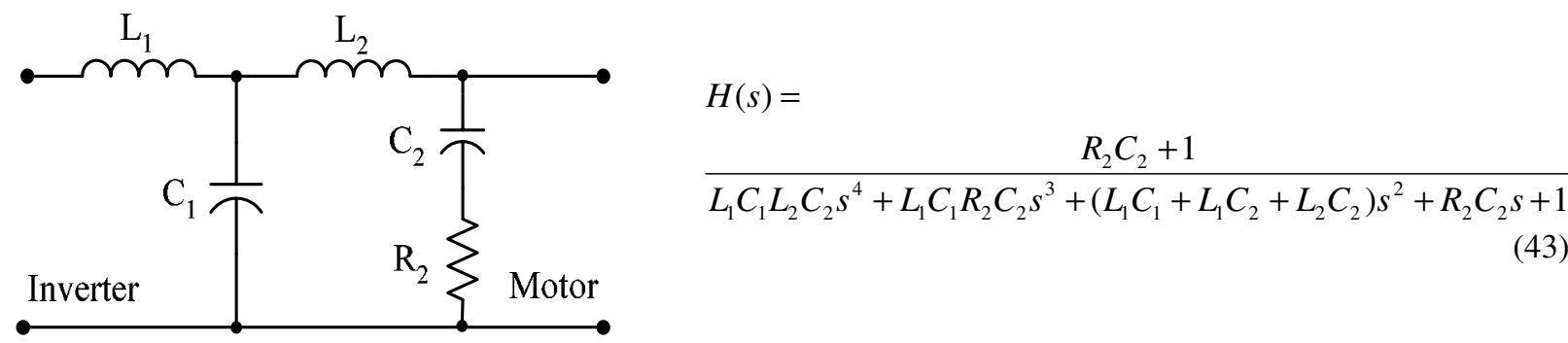

Figure 9. Single Phase Circuit for the Two-Stage R-L-C Filter

The cut-off frequency at each stage can be expressed with the following equation 


$$
f_{c}=\frac{1}{2 \pi \sqrt{L C}}
$$

were $L$ and $C$ are the inductance and capacitance of the L-C-R filter for the first stage or the second stage. The cutoff frequency for this flywheel application was selected between the maximum fundamental frequency of the M/G $(1 \mathrm{kHz})$ and the inverter switching frequency $(65 \mathrm{kHz})$ assuring minimum phase lag impact in the operating region of 0 and $1 \mathrm{kHz}$ and large high attenuation at high frequencies. Bode plots are made to confirm that the filter satisfies the requirements

A cut-off frequency $\left(f_{c}\right)$ of $10 \mathrm{kHz}$ was selected for our flywheel M/G application. Figure 10 depicts the Bode plot of a $10 \mathrm{kHz}$ two-stage R-L-C filter. This L-C-R filter Bode plot shows no attenuation or amplification with minimum phase lag impact at frequencies below or equal to $1 \mathrm{kHz}$. At frequencies above $10 \mathrm{kHz}$ filter the signal attenuates at an approximate rate of $60 \mathrm{~dB}$ per decade. At the inverter $65 \mathrm{kHz}$ switching frequency the attenuation is $47 \mathrm{~dB}$. The phase plot shows a lagging effect at high frequency but no impact in the M/G operating frequency range.
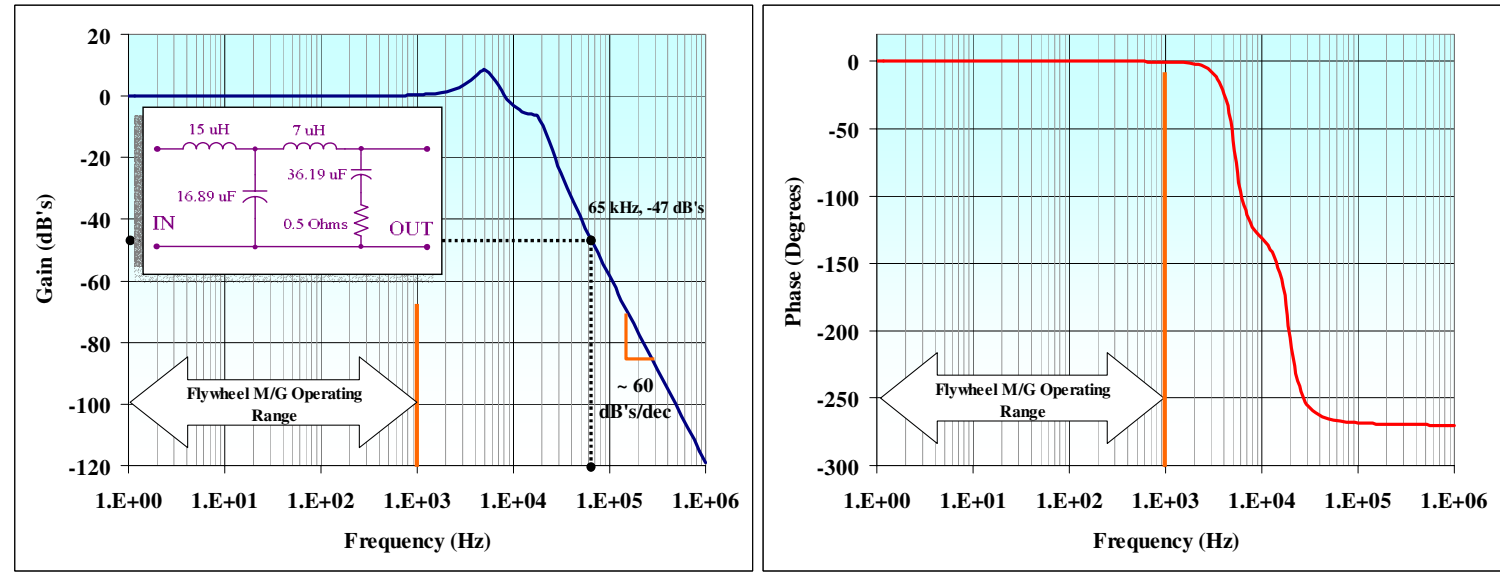

Figure 10.

Bode Plot of a $10 \mathrm{kHz}$ Two-stage R-L-C Filter

The filter inductance values were deliberately kept low in the filter design to minimize the filter output impedance within the operating range of frequencies $(0$ to $1 \mathrm{kHz})$. A large output impedance is undesirable for two reasons. One is the phase shift would introduce a lag in the motor control loop. Second the voltage drop across the output impedance would reduce the maximum voltage available to the motor which limits the motor acceleration at high speeds [9]. Thus the filter series inductors, $L_{1}$ and $L_{2}$, were designed so their sum is below the motor inductance value. The R, L's and C's values for the proposed two-stage R-L-C filter can be seen on figure 10 and these are:

$$
\begin{array}{ll}
L_{1}=15 \mu-\mathrm{H}, & C_{1}=16.99 \mu-\mathrm{F} \\
L_{2}=7 \mu-\mathrm{H}, & C_{2}=36.19 \mu-\mathrm{F} \quad \text { and } \quad R_{2}=0.5 \Omega .
\end{array}
$$

The sum of both inductors, $L_{1}+L_{2}$, is $23 \mu-\mathrm{H}$ which is smaller than the phase $\mathrm{M} / \mathrm{G}$ winding inductance $(33.5 \mu-\mathrm{H})$. The capacitance values were obtained by using equation (44) based on the $L_{1}, L_{2}$ values and the $10 \mathrm{kHz}$ cut-off frequency. Since the values of the inductors are low, the capacitance value should be large in order to satisfy the $10 \mathrm{kHz}$ cut-off frequency. The large value capacitors also provide the benefit of reducing the CM voltage as shown in equation (42) when connecting the filter neutral $(N)$ to the DC-Link mid-point "o". See also figure 7 for the system topology.

\section{B. Design of a Two-Stage R-L-C Filter Topology with an L-C Trap Filter}

The AC filter topology can be augmented with an L-C trap filter between the inverter and the two-stage R-L-C filter, see figure 11. The purpose of an L-C trap filter is to further reduce the switching frequency harmonic of the inverter by introducing a high impedance path [8] between the inverter and the M/G. The values of the inductor $\left(L_{T}\right)$ and the capacitor $\left(C_{T}\right)$ are tuned using equation (44) with the cut-off frequency, $f_{c}$, set to the switching frequency of the inverter MOSFETs. The bode plot (fig. 12) of the R-L-C filter low pass and L-C trap filter shows more than 
twice the attenuation (more than $100 \mathrm{~dB}$ ) at the $65 \mathrm{kHz}$ switching frequency compared to the two-stage R-L-C filter gain plot at the same frequency ( $47 \mathrm{~dB}$ in fig. 10$)$.

This topology produces some amplification (maximum of $2 \mathrm{~dB}$ ) between $200 \mathrm{~Hz}$ and $1 \mathrm{kHz}$ and some phase lag between 300 and $1 \mathrm{kHz}$ (maximum lag of -1.18 degrees). Even though the trap filter introduced a gain and phase effect on the system this does not introduce a major impact to the $\mathrm{M} / \mathrm{G}$ control loop system due to their small values [9]. On the other hand, the very high impedance value of the L-C trap filter at the switching frequency greatly reduces the leakage current $\left(I_{p}\right)$ in the parasitic capacitance $\left(C_{p}\right)$ of the flywheel M/G. In addition, the amount of switching frequency voltage between the DC link mid-point capacitor "o" and the system ground $\left(V_{o g}\right)$ is reduced. This provides lower common mode voltage, thus reducing the negative effects of the high $\mathrm{dv} / \mathrm{dt}$ listed in the introduction section of this paper (see also fig. 5(d)).

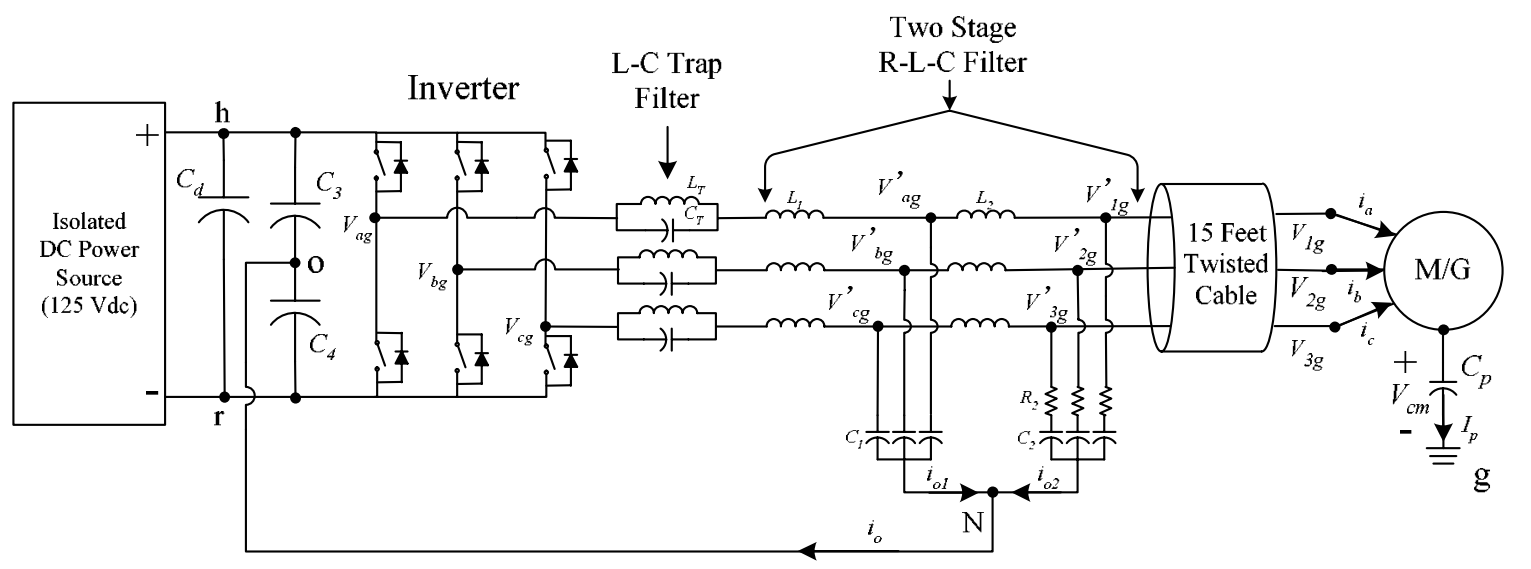

Figure 11. Proposed Three Phase R-L-C Filter with an L-C Trap for the Flywheel M/G and Inverter System
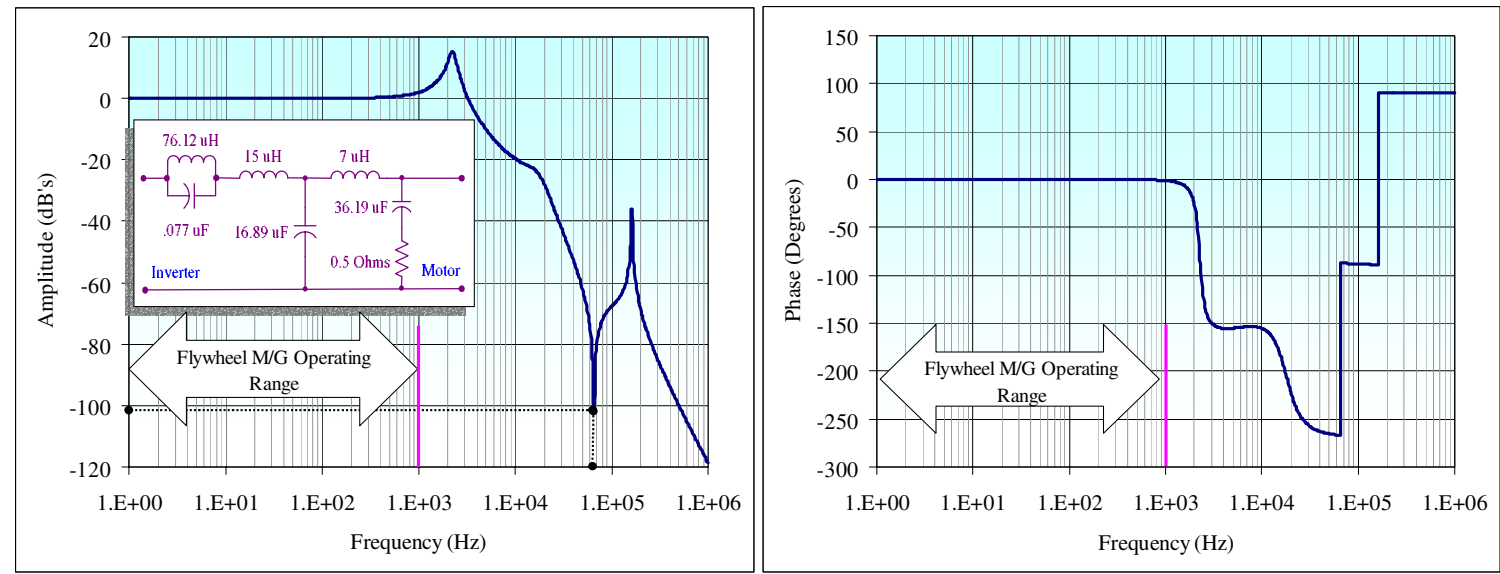

Figure 12. Bode Plot of a $10 \mathrm{kHz}$ Two-stage R-L-C Filter and a $65 \mathrm{kHz}$ L-C Trap

\section{Test Results}

Three filter topologies and the no-filter configurations were selected to test and compare the impact of the different filter topologies on the CM and DM voltages. The four filter topologies were

- No filter

- Two-Stage $10 \mathrm{kHz}$ R-L-C filter with $\boldsymbol{N O}$ connection between its neutral $(N)$ and the DC Link MidPoint "o" (figs. 6 and 7).

- Two-Stage $10 \mathrm{kHz}$ R-L-C filter with a connection between its neutral $(N)$ and the DC Link Mid-Point "o" (fig. 7).

- Two-Stage $10 \mathrm{kHz}$ R-L-C filter plus a $65 \mathrm{kHz}$ L-C trap with a connection between its neutral $(N)$ and the DC Link Mid-Point "o" (fig. 11). 


\section{A. Differential Mode (DM) Test Results}

Figure 13 shows the line to line voltage when the flywheel system is spinning at 55,000 rpm or at a fundamental frequency of $917 \mathrm{~Hz}$. Clearly the effect of the two-stage R-L-C filter at the differential mode can be seen. A near sinusoidal waveform has been obtain thus no high $\mathrm{dv} / \mathrm{dt}$ voltage will reach at the motor windings and the voltage stresses have been eliminated. This improvement of the differential mode holds whether a connection between the filter neutral and DC point "o" has been made or not.

It is also important to point out that if a filter is absent high dv/dt will travel trough the line creating the M/G winding stresses due to the voltage doubling effect and also increasing leakage current.

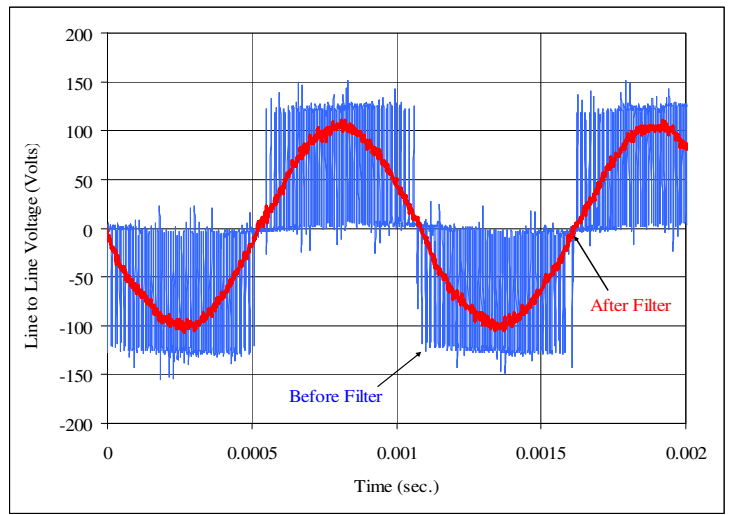

Figure 13. M/G Line to Line Voltage Before and After the Two-Stage R-L-C Filter when the Flywheel is Spinning at 55,000 rpm or at a Fundamental Frequency of $917 \mathrm{~Hz}$.

\section{B. Leakage Current Tests Results- $\left(I_{p}\right)$}

Although $V_{c m}$ cannot be measured directly to confirm equations (13), (25) and (42), it is still possible to evaluate its effect by measuring the leakage current $\left(I_{p}\right)$ and the parasitic capacitance, $C_{p}$, between the motor stator windings and the flywheel main housing. $I_{p}$ can be easily measured under the different topology conditions by using a current probe at the flywheel ground cable (see fig. 11) and $C_{p}$ by using an Impedance Measuring System (IMS).
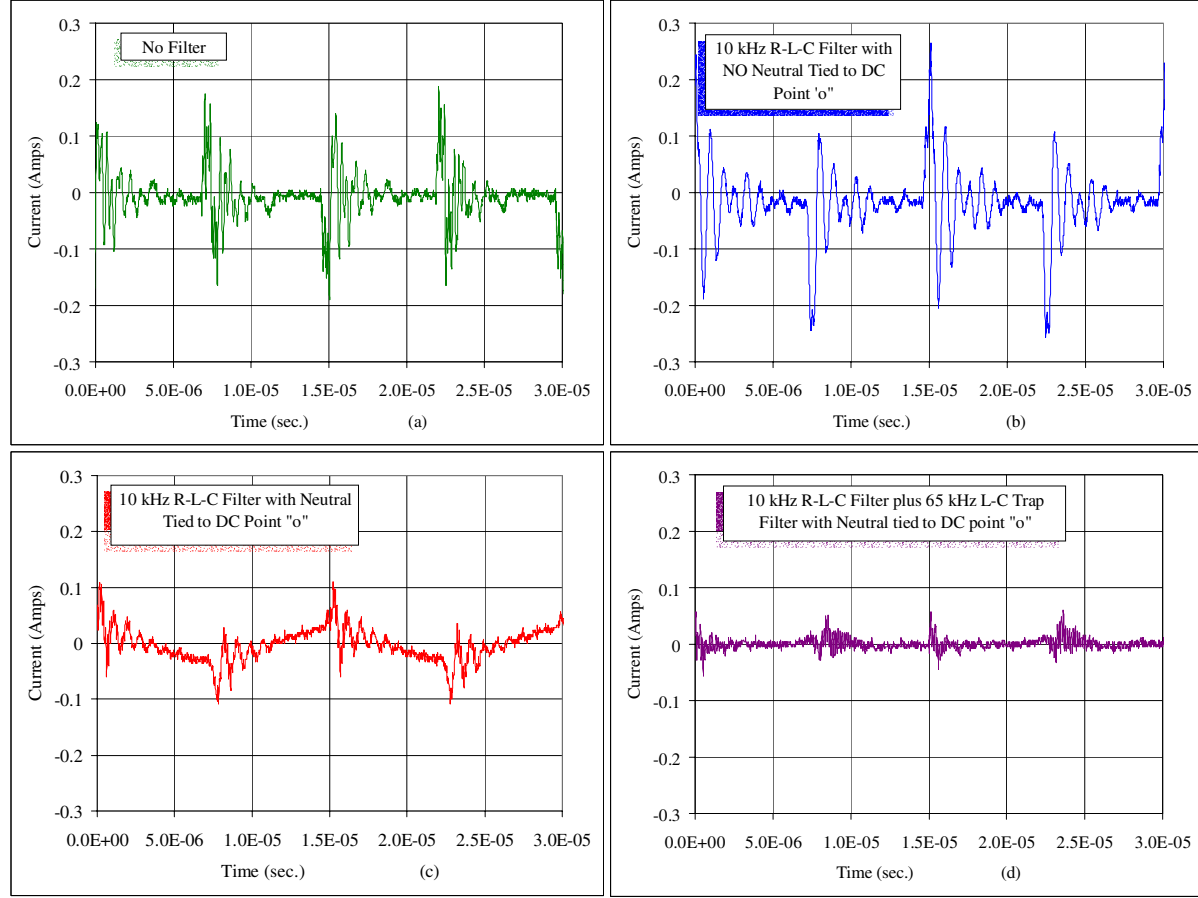

Figure 14. $\quad$ M/G Leakage current $\left(I_{p}\right)$ Frequency Spectrum

(a) No Filter, (b) $10 \mathrm{kHz}$ R-L-C Filter with NO Neutral Tied to "o",

(c) $10 \mathrm{kHz}$ R-L-C Filter with Neutral Tied to "o" and

(d) $10 \mathrm{kHz}$ R-L-C Filter plus $65 \mathrm{kHz}$ L-C Filter with Neutral Tied to "o" 
Figure 14 shows the leakage current measurements with different filter topologies. With the no filter topology (fig. 14(a)) and in the floating R-L-C filter topology (fig. 14(b)), high frequency leakage current is present. This will produce noise propagation that the MB position sensors are vulnerable to. This noise on the position sensors is caused by high $\mathrm{dv} / \mathrm{dt}$ at the common mode voltage across the parasitic capacitor resulting in leakage current to freely flowing (eq. (13) and (24)).In contrast, the case in which the two-stage 10-kHz R-L-C filter is employed with its neutral point " $N$ " is connected to the DC link mid-point "o" (fig. 14(c)), all the high frequency leakage currents have been significantly attenuated. However, the inverter $65 \mathrm{kHz}$ switching component is still present although at a lesser amplitude. In figure 14(d) when a $65 \mathrm{kHz} \mathrm{L-C}$ Trap filter is applied in addition to the $10 \mathrm{kHz}$ R-L-C filter, the $65 \mathrm{kHz}$ inverter switching effect is almost eliminated as a result of the high impedance path of the trap filter. This further reduces the noise interference on the flywheel system.

Figures 15 (a), (b), (c) and (d) also shows the leakage current of the different filter topologies in the frequency domain. Again, figures 15 (c) and (d) show a major leakage current reduction at the high frequency harmonics of the $65 \mathrm{kHz}$ inverter but again, only when the trap filter is applied the $65 \mathrm{kHz}$ frequency component is significantly reduced. In conclusion, when the filter neutral point is connected to the DC link mid-point "o" $V_{o g}$ becomes more sinusoidal (less noisy). In accordance with CM voltage equation (42) and figure 5 the values of $L_{1}, C_{l}, L_{2}, C_{2}$ and $R_{2}$ can be also selected to help reduced the CM voltage.

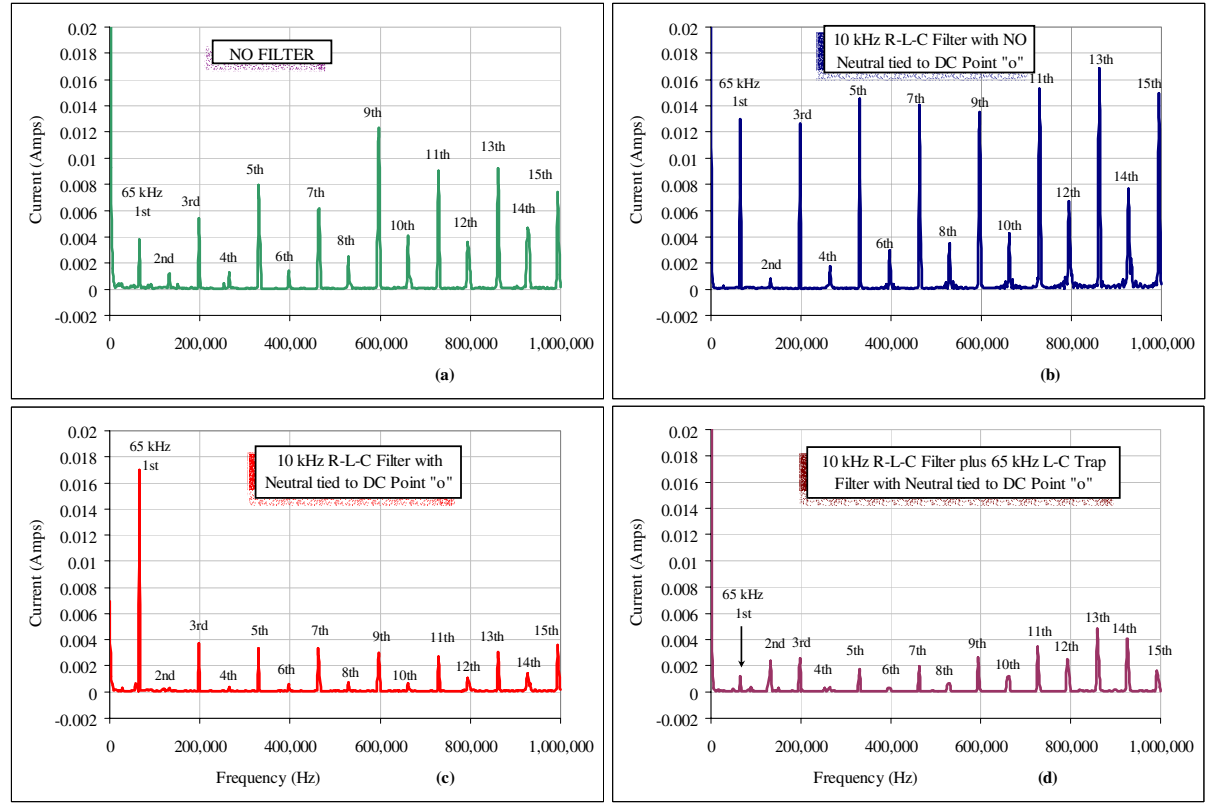

Figure 15. $\quad$ M/G Leakage current $\left(I_{p}\right)$ Frequency Spectrum

(a) No Filter, (b) $10 \mathrm{kHz}$ R-L-C Filter with NO Neutral Tied to "o",

(c) $10 \mathrm{kHz}$ R-L-C Filter with Neutral Tied to "o",

(d) $10 \mathrm{kHz}$ R-L-C Filter plus $65 \mathrm{kHz}$ L-C Filter with Neutral Tied to "o"

To measure the leakage capacitance, $C_{p}$, between the $\mathrm{M} / \mathrm{G}$ and the flywheel main housing an Impedance Measuring System (IMS) was used (fig. 16). The IMS consists of a frequency response analyzer and a computer to fully automate the frequency sweep through a given band. By connecting all the M/G Terminals in a single node and using the flywheel main chassis as the return, the IMS will perform the frequency sweep while measuring the voltage and current. The computer control software divides the voltage and current to display the impedance of the test article.

Figure 17 shows the results of the IMS measurements. The leakage capacitance and the inductance of the M/G windings start to interact with a minimum impedance point at $1.731 \mathrm{MHz}$. At this resonant point the leakage capacitance $\left(C_{p}\right)$ is around 13.27 nano-Farads. This measured value then can be used for future system simulation. 


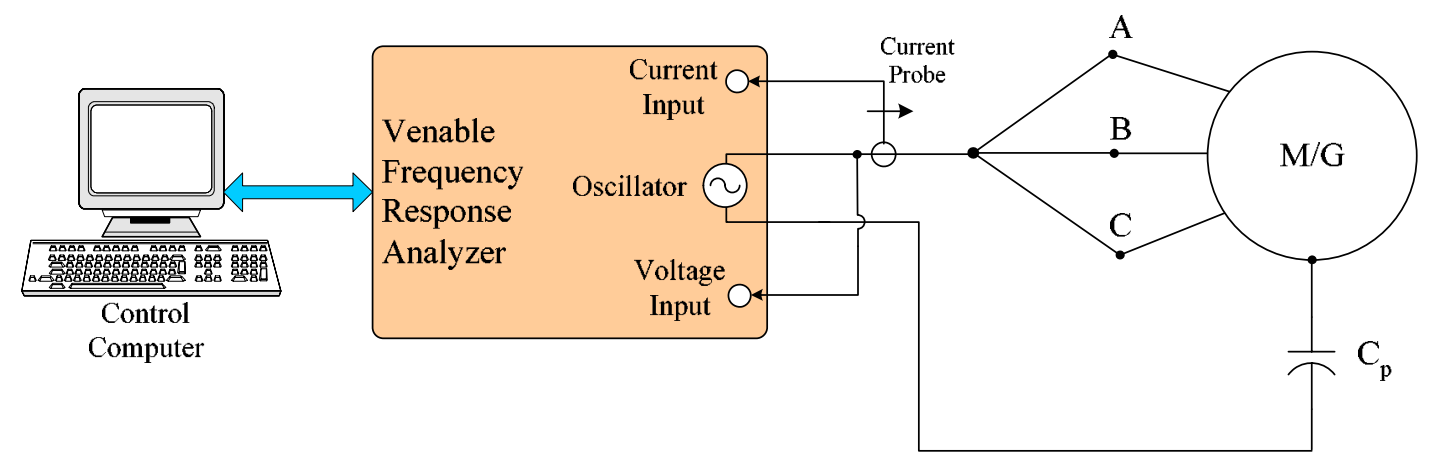

Figure 16. Impedance Measuring System (IMS) Set Up for M/G Leakage Capacitance Measurement

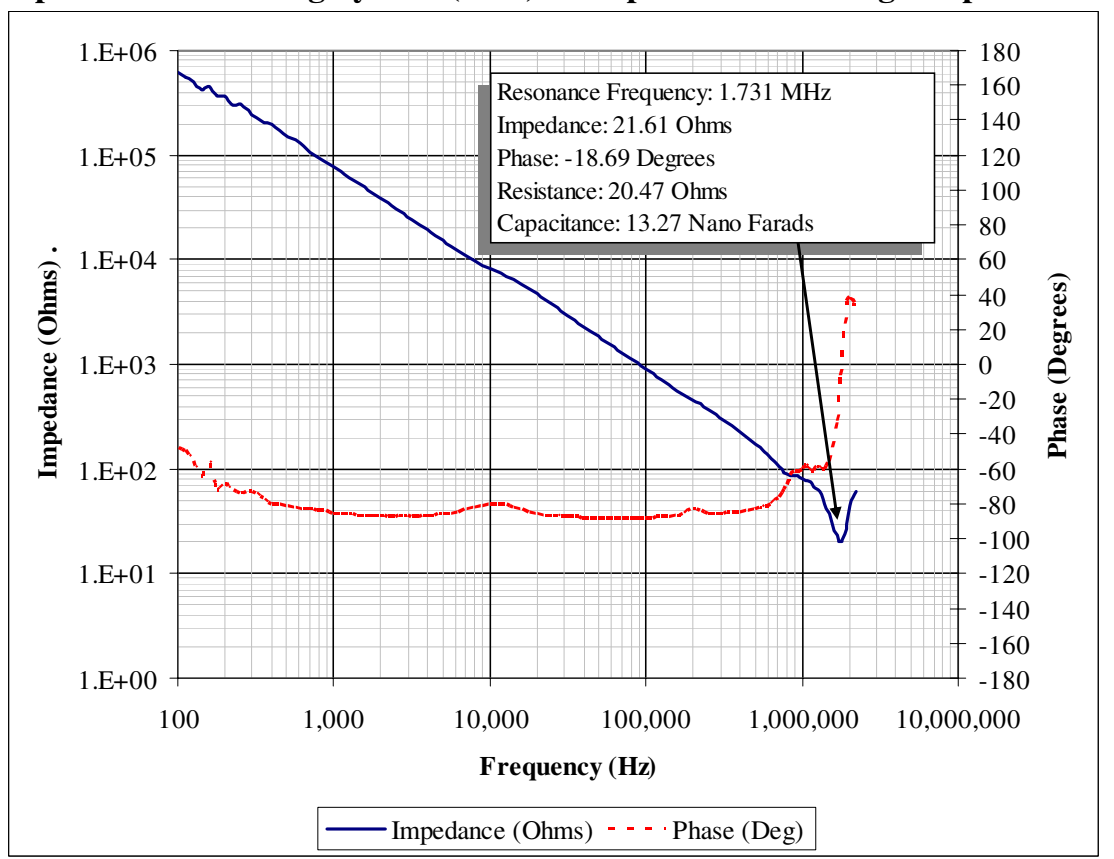

Figure 17. Flywheel Motor/Generator Leakage Capacitance $\left(C_{p}\right)$ Measurement

\section{Magnetic/Bearings Position sensors test results}

As mentioned in the introduction, the importance of having a clean feedback signal of every eddy-current position sensors is crucial for the success of spinning the flywheel rotor up to $60,000 \mathrm{rpm}$. By applying an R-L-C filter with its neutral attached to the DC link mid-point "o" it gives a desirable solution of containing the noise right at the source rather than applying extra filtering at the receiving end of the position measurement. In the magnetic bearing section of figure 1 it can be seen that the measurements of the position signal feedback were made before a gain and offset board at the labeled "X1 Test Point". This gives a raw measurement with no previous processing and filtering.

Figures 18 and 19 shows the effect of the different AC filter topologies on the MB position sensors, in the time and frequency domain respectively. Clearly when no filters are being used, a large amount of high frequency noise is present (figs. 18(a) and 19(a)). With this much noise on the position sensors, the MB system cannot work reliably.

When a floating R-L-C filter is applied some reduction of high frequency noise on the position sensors was noticeable (figs. 18(b) and 19(b)). Even though an improvement has been made, high frequency harmonics are still present. In this configuration, the voltage components due to the eight switching states and $V_{\text {og }}$ are still high (eq. (25) and fig. 5(b)). Again, applying an R-L-C filter with no connection to the DC mid-point "o" does not reduce noise enough to provide a very clean position signal.

The impact of connecting the R-L-C filter neutral $(N)$ to the DC Link Mid-Point "o" can be seen clearly in figures 18(c), (d) and figures 19 (c) and (d). A great amount of high frequency noise at the position sensors has been 
eliminated making it easier for the MB control system to operate. This is the result of reducing the high frequency content of $\mathrm{V}_{\text {og }}$ through the proper selection of the R-L-C components (eq. (42) and fig. 5(c) and (d)).
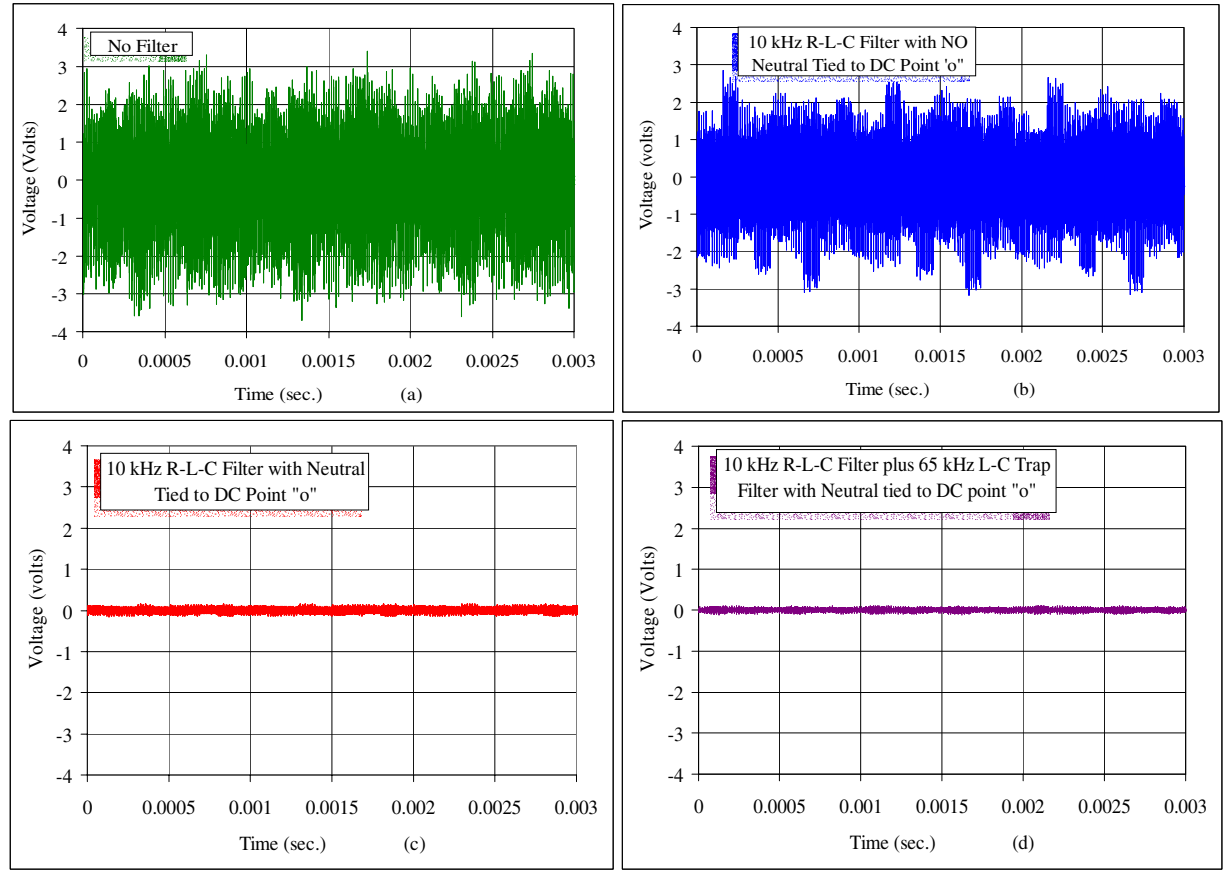

Figure 18. Magnetic Bearing Position Sensor versus Time

(a) Inverter On with No Filter, (b) Inverter On with $10 \mathrm{kHz}$ R-L-C Filter with NO Neutral Tied to "o",

(c) Inverter On with $10 \mathrm{kHz}$ R-L-C Filter with Neutral Tied to "o"

(d) Inverter On with $10 \mathrm{kHz}$ R-L-C Filter plus $65 \mathrm{kHz}$ L-C Filter with Neutral Tied to "o"
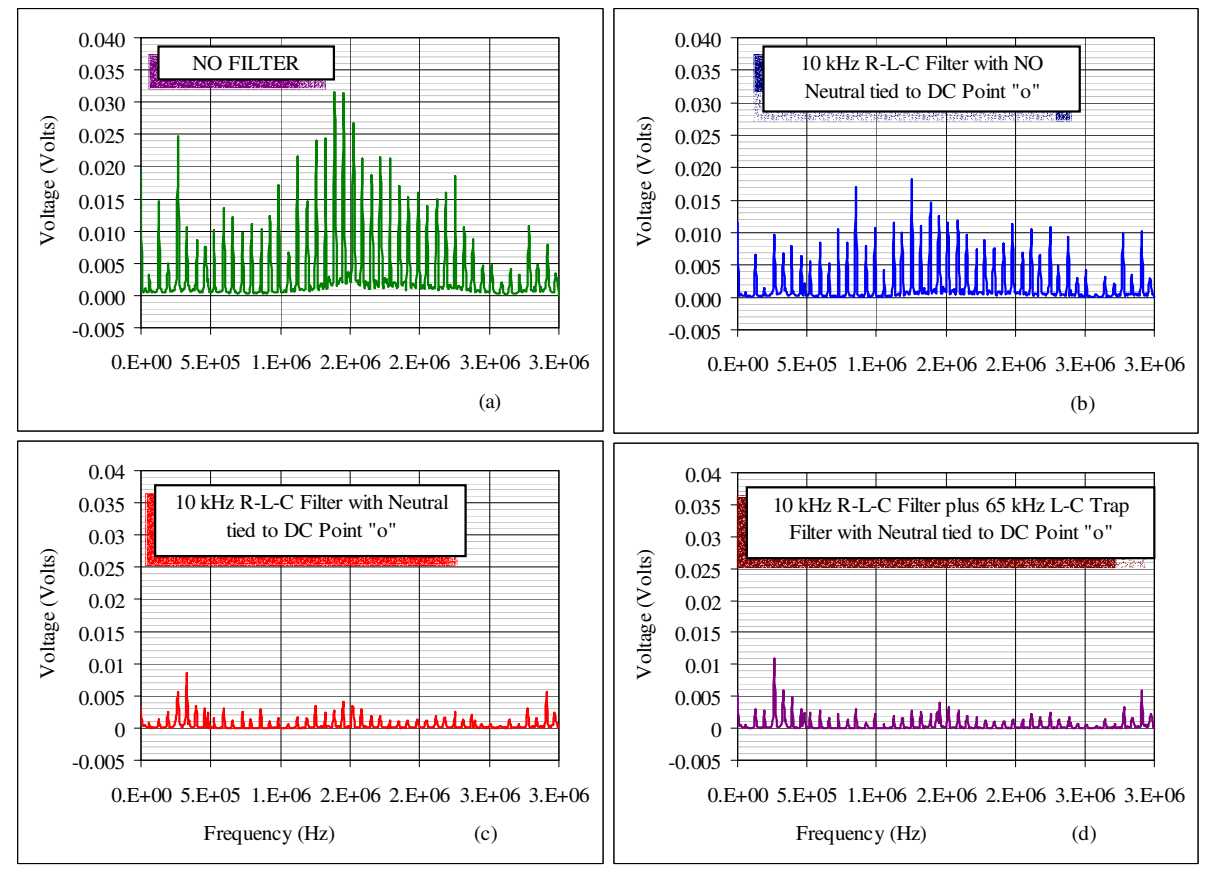

Figure 19. Magnetic Bearing Position Sensor ( $\mathrm{X}$ axis) Frequency Spectrum

(a) Inverter On with No Filter, (b) Inverter On with $10 \mathrm{kHz}$ R-L-C Filter with NO Neutral Tied to "o",

(c) Inverter On with $10 \mathrm{kHz}$ R-L-C Filter with Neutral Tied to "o"

(d) Inverter On with $10 \mathrm{kHz}$ R-L-C Filter plus $65 \mathrm{kHz}$ L-C Filter with Neutral Tied to "o" 
When monitoring the position sensors of the flywheel system, several oscilloscopes set in X-Y mode are used (fig. 1). Figure 20(a) and (b) show the position sensor readings when the R-L-C filter has the neutral attached to the mid point "o" and with the neutral floating respectively. The scales of the position sensors are approximately 0.28 Volts per thousand of an inch $(0.28 \mathrm{~V} / \mathrm{mils})$, and the total displacement before the flywheel shaft hits the touchdown bearings is 8 mils. By looking at figure 20(b) it is clear that common mode noise can provide false displacement measurements of about 2.14 mils on the $\mathrm{X}$ and $\mathrm{Y}$ axis or almost $30 \%$ of the total displacement. This measurement was also taken after an $8 \mathrm{kHz}$ low pass filter has been. This is a clear indication that containing the high dv/dt noise at its source, the inverter in this case, is preferable than trying to filter it at the receiving end of the MB feedback signals.

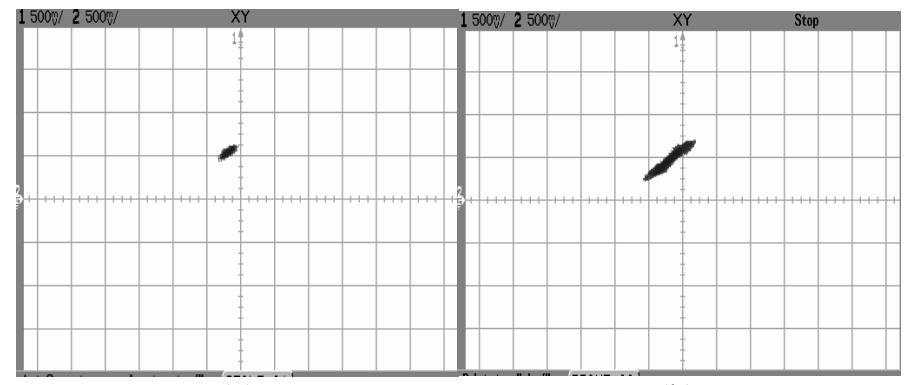

(a)

(b)

Figure 20. Magnetic Bearing Position Sensor in an X-Y scope. X and Y Scale of 0.5V/div.

(a) Two-stage R-L-C Filter with Neutral Attached to the DC Link Mid-point "o"

(b) Floating Two-stage R-L-C Filter

\section{Motor/Generator Phase Current Test Result}

Phase current ripple that flows into the $\mathrm{M} / \mathrm{G}$ windings also has an effect. The larger the ripple current the more heating at the $\mathrm{M} / \mathrm{G}$ stator is being generated. The amount of ripple that is generated is influenced by the total inductive reactance of the motor windings plus the line and the R-L-C filter inductance $\left(X_{L}=j \omega L\right)$. The filter without the trap reduces some of the high frequency motor current ripple as can be seen in figure 21(a). This is expected given the highly sinusoidal voltage that is applied to the motor after the filter (see fig. 13). But if a $65 \mathrm{kHz}$ L-C trap filter is used in addition to the R-L-C filter, the total impedance at the switching frequency will increase significantly thus reducing the $65 \mathrm{kHz}$ current ripple amplitude even more. The effect of the L-C trap can be easily seen in figure 21, where the frequency spectra of the motor phase current using the two filter topologies were measured. Figure 21(b) shows that the use of the L-C trap filter considerably reduces the $65 \mathrm{kHz}$ switching effect on the $\mathrm{M} / \mathrm{G}$ line current.
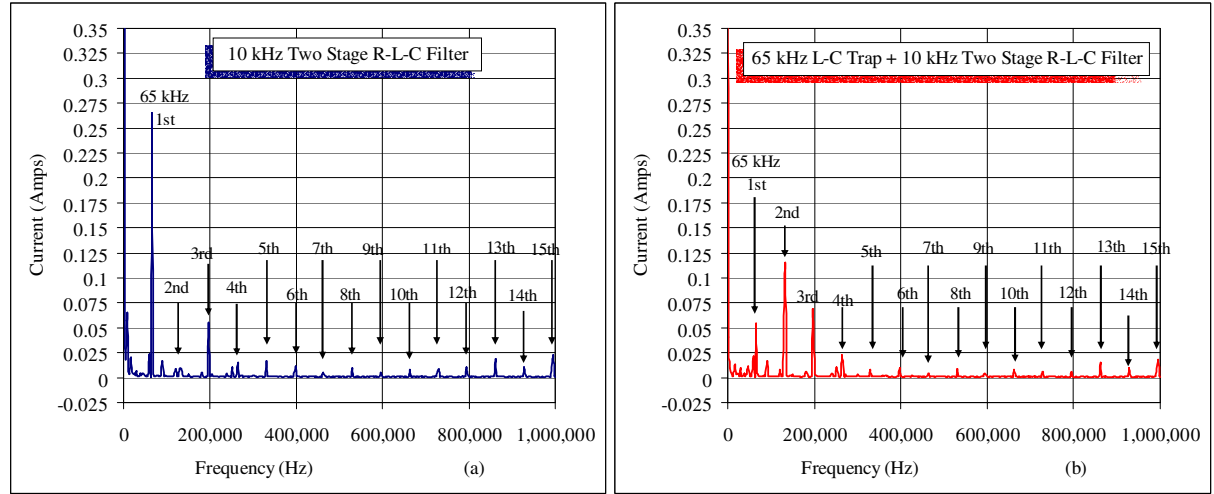

Figure 21. M/G Line Current Frequency Spectrum

(a) $10 \mathrm{kHz}$ Two-Stage R-L-C Filter, (b) $65 \mathrm{kHz}$ l-C Trap plus $10 \mathrm{kHz}$ Two-Stage R-L-C Filter 


\section{Conclusions}

The use of a two-stage R-L-C filter with its neutral connected to the DC link mid-point "o" proved to be advantageous for the flywheel motor/generator $(\mathrm{M} / \mathrm{G})$ system and the magnetic bearing $(\mathrm{MB})$ system in reducing the common mode (CM) and differential mode (DM) without affecting the M/G control loop. Noise in the M/G system caused by the DC to AC inverter high dv/dt switching is reduced by designing the values of the R-L-C filter elements to acquire a near sinusoidal line to line waveform. Voltage stresses and the voltage doubling effect at the motor terminals have also been considerably reduced. By connecting the R-L-C filter neutral to the DC link midpoint "o" the high frequency components of the leakage current are minimized thus reducing the risk of EMI in the flywheel internal avionics.

Most importantly, noise in the magnetic bearing eddy current position sensors has been significantly reduced, consequently allowing reliable operation of the flywheel up to $60,000 \mathrm{rpm}$. With the addition of the L-C trap filter, a high impedance path has been provided at the inverter's $65 \mathrm{kHz}$ switching frequency thereby reducing the $65 \mathrm{kHz}$ components of the leakage current $\left(I_{p}\right)$ and the motor phase current resulting in more efficient and less noisy M/G operation.

\section{References}

${ }^{1}$ Kenny, Barbara H., Jansen, Ralph, Kasack, Peter, E., Dever, Timothy, and Santiago, Walter, "Demonstration of Single Axis Combined Attitude Control and Energy Storage Using Two Flywheels," NASA/TM-2004-212935.

${ }^{2}$ Murai, Y., Kubota, T., and Kawase, Y., "Leakage current reduction for a high-frequency carrier inverter feeding an induction motor," IEEE Transactions on Industry Applications, vol. 28, pp.858-863, July/August 1992.

${ }^{3}$ Ogasawara S. and Akagi H, "Modeling and damping of high-frequency leakage currents in PWM inverter-fed ac motor drive systems," IEEE IAS Conference Rec., 1995, pp. 29-36.

${ }^{4} J u l i a n$, A. L. and Lipo, T. A., "Elimination of common mode voltage in three phase sinusoidal power converters," IEEE PES Conference Rec., 1996, pp. 1968-1972.

${ }^{5}$ Kazonori, Y., Fujita, H., and Akagi, H., “A reduction method of high frequency leakage current from a PM motor drive system using a PWM inverter,". IEE Japan Conference Rec., October 1992.

${ }^{6}$ Rendusara, Dudi A. and Enjeti, Prasad N., "An improved inverter output filter configuration reduces common and differential modes dv/dt at the motor terminals in PWM drive systems," IEEE Transactions on Power Electronics, Vol. 13, No. 6, November 1998, pp. 1135-1143.

${ }^{7}$ von Jouanne A. and Enjeti, Prasad N., "Design considerations for an inverter output filter to mitigate the effects of long leads in ASD applications," IEEE Transactions on Industry Applications, Vol. 33, pp. 1138-1145.

${ }^{8}$ Sozer Yilmaz, Torrey, David A., and Reva, Suhan, "New inverter output filter topology for PWM motor drives," IEEE Transactions on Power Electronics, Vol. 15, No. 6, November 2000, pp. 1007-1017.

${ }^{9}$ Kenny, Barbara H. and Santiago, Walter, "Filtering and Control of High Speed Motor Current in a Flywheel Energy Storage System," International Energy Conversion Engineering Conference (IECEC), August 16-19 2004. 
Public reporting burden for this collection of information is estimated to average 1 hour per response, including the time for reviewing instructions, searching existing data sources, gathering and maintaining the data needed, and completing and reviewing the collection of information. Send comments regarding this burden estimate or any other aspect of this collection of information, including suggestions for reducing this burden, to Washington Headquarters Services, Directorate for Information Operations and Reports, 1215 Jefferson Davis Highway, Suite 1204, Arlington, VA 22202-4302, and to the Office of Management and Budget, Paperwork Reduction Project (0704-0188), Washington, DC 20503.

\begin{tabular}{|l|l|l|}
\hline 1. AGENCY USE ONLY (Leave blank) & $\begin{array}{c}\text { 2. REPORT DATE } \\
\text { September } 2004\end{array}$ & $\begin{array}{r}\text { 3. REPORT TYPE AND DATES COVERED } \\
\text { Technical Memorandum }\end{array}$ \\
\hline
\end{tabular}

\section{TITLE AND SUBTITLE}

Inverter Output Filter Effect on PWM Motor Drives of a Flywheel Energy Storage System

6. AUTHOR(S)

Walter Santiago

\section{PERFORMING ORGANIZATION NAME(S) AND ADDRESS(ES)}

National Aeronautics and Space Administration

John H. Glenn Research Center at Lewis Field

Cleveland, Ohio 44135-3191

\section{FUNDING NUMBERS}

WBS-22-319-20-M1

\section{SPONSORING/MONITORING AGENCY NAME(S) AND ADDRESS(ES)}

National Aeronautics and Space Administration

Washington, DC 20546-0001
8. PERFORMING ORGANIZATION REPORT NUMBER

E-14748

\section{SUPPLEMENTARY NOTES}

Prepared for the Second International Energy Conversion Engineering Conference sponsored by the American Institute of Aeronautics and Astronautics, Providence, Rhode Island, August 16-19, 2004. Responsible person, Walter Santiago, organization code 5450, 216-433-8486.

\section{2a. DISTRIBUTION/AVAILABILITY STATEMENT}

12b. DISTRIBUTION CODE

Unclassified - Unlimited

Subject Categories: 20, 33, and 07

Distribution: Nonstandard

Available electronically at http://gltrs.grc.nasa.gov

This publication is available from the NASA Center for AeroSpace Information, 301-621-0390.

\section{ABSTRACT (Maximum 200 words)}

NASA Glenn Research Center (GRC) has been involved in the research and development of high speed flywheel systems for small satellite energy storage and attitude control applications. One research and development area has been the minimization of the switching noise produced by the pulsed width modulated (PWM) inverter that drives the flywheel permanent magnet motor/generator (PM M/G). This noise can interfere with the flywheel $\mathrm{M} / \mathrm{G}$ hardware and the system avionics hampering the full speed performance of the flywheel system. One way to attenuate the inverter switching noise is by placing an AC filter at the three phase output terminals of the inverter with the filter neutral point connected to the DC link (DC bus) midpoint capacitors. The main benefit of using an AC filter in this fashion is the significant reduction of the inverter's high dv/dt switching and its harmonics components. Additionally, common mode $(\mathrm{CM})$ and differential mode (DM) voltages caused by the inverter's high dv/dt switching are also reduced. Several topologies of AC filters have been implemented and compared. One AC filter topology consists of a two-stage R-L-C low pass filter. The other topology consists of the same two-stage R-L-C low pass filter with a series connected trap filter (an inductor and capacitor connected in parallel). This paper presents the analysis, design and experimental results of these AC filter topologies and the comparison between the no filter case and conventional AC filter.

14. SUBJECT TERMS

Flywheel, PWM inverter, Motor/generator RLC filter, dv/dt switching, Common and differential modes, Filter

\begin{tabular}{|c|c|}
\hline $\begin{array}{c}\text { 17. SECURITY CLASSIFICATION } \\
\text { OF REPORT } \\
\text { Unclassified }\end{array}$ & $\begin{array}{c}\text { 18. SECURITY CLASSIFICATION } \\
\text { OF THIS PAGE } \\
\text { Unclassified }\end{array}$ \\
\hline
\end{tabular}

19. SECURITY CLASSIFICATION OF ABSTRACT Unclassified

\section{NUMBER OF PAGES}

16. PRICE CODE

20. LIMITATION OF ABSTRACT 

